\title{
Temperature correction and usefulness of ocean bottom pressure data from cabled seafloor observatories around Japan for analyses of tsunamis, ocean tides, and low-frequency geophysical phenomena
}

\author{
Daisuke Inazu and Ryota Hino \\ Research Center for Prediction of Earthquakes and Volcanic Eruptions, Graduate School of Science, Tohoku University,
6-6 Aza-Aoba, Aramaki, Aoba-ku, Sendai 980-8578, Japan \\ (Received March 23, 2011; Revised July 16, 2011; Accepted July 22, 2011; Online published February 14, 2012)
}

\begin{abstract}
Ocean bottom pressure (OBP) data obtained by cabled seafloor observatories deployed around Japan, are known to be significantly affected by temperature changes. This paper examines the relationship between the OBP and temperature records of six OBP gauges in terms of a regression coefficient and lag at a wide range of frequencies. No significant temperature dependency is recognized in secular variations, while substantial increases, at rates of the order of $1 \mathrm{hPa} /$ year, are commonly evident in the OBP records. Strong temperature dependencies are apparent for periods of hours to days, and we correct the OBP data based on the estimated OBP-temperature relationship. At periods longer than days, the temperature corrections work well for extracting geophysical signals for OBP data at a station off Hokkaido (KPG2), while other corrected data show insufficient signal-to-noise ratios. At a tsunami frequency, the correction can reduce OBP fluctuations, due to rapid temperature changes, by as much as millimeters, and is especially effective for data at a station off Shikoku (MPG2) at which rapid temperature changes most frequently occur. A tidal analysis shows that OBP data at a station off Honshu (TM1), and at KPG2, are useful for studies on the long-term variations of tidal constituents.

Key words: Ocean bottom pressure, temperature correction, tsunami, ocean tide, oceanic variation.
\end{abstract}

\section{Introduction}

Pressure sensor units for oceanographic applications have been employed since the late 1960's (e.g., Munk and Zetler, 1967). Various types of pressure transducers have been investigated for obtaining high-quality ocean bottom pressure (OBP) records. These include vibrating wires, strain gauges, capacitance plates, and quartz-crystal resonators. The quartz-crystal resonator transducer is most commonly used at present because of its high sensitivity to pressure, high resolution, and long-term stability (Eble et al., 1989; Joseph, 2011). Devices incorporating the quartz resonator manufactured by Paroscientific, Inc. (hereafter Paros), and by Hewlett-Packard, Inc. (hereafter HP), are currently used as water-depth sensors. In general, the physical pressure measurement is obtained from the vibrational frequency of the transducer, which changes with ambient pressure and temperature. Therefore, thermal effects must be accurately corrected to obtain a meaningful physical pressure value. A built-in thermometer is needed to accurately measure the temperature of the transducer. The manufacturers provide conversion equations, and tables of calibration coefficients, to calculate an accurate physical pressure value, with a thermal correction, from the vibrational frequency, for the respective sensors. The procedures to obtain the physical pressure value with a pressure-

Copyright (C) The Society of Geomagnetism and Earth, Planetary and Space Sciences (SGEPSS); The Seismological Society of Japan; The Volcanological Society of Japan; The Geodetic Society of Japan; The Japanese Society for Planetary Sciences; TERRAPUB.

doi:10.5047/eps.2011.07.014 measurement system were introduced by Eble et al. (1989) for the Paros sensors, and by Takahashi (1981a) for the HP sensors.

After many field and laboratory experiments (e.g., Wearn and Larson, 1982; Wearn and Paros, 1988; Houston and Paros, 1998) partially conducted by the Scientific Committee on Oceanic Research (SCOR, 1975), the Paros sensor, incorporating the Bourdon tube (Filloux, 1970), was highly improved, and has been called the Digiquartz pressure sensor. The pressure gauges derived from the Paros measurement system have demonstrated good performances for observing tsunamis of the order of millimeters (Filloux, 1982), ocean tides (Mofjeld and Wimbush, 1977), and lowfrequency $\left(<1\right.$ day $\left.^{-1}\right)$ oceanic variations of the order of centimeters (Niiler et al., 1993) (in general, a 1-cm seawater height is equivalent to $1 \mathrm{hPa}$ ). At present, the Paros pressure gauges are widely used for oceanographic (e.g., Spencer and Vassie, 1997; Park and Watts, 2005; Park et al., 2008; Uchida and Imawaki, 2008) and geodetic (e.g., Fox, 1990; Fujimoto et al., 2003; Chadwick et al., 2006; Matsumoto et al., 2006; Nooner and Chadwick, 2009) applications. The Deep-ocean Assessment and Reporting of Tsunamis (DART) system, operated by the Pacific Marine Environmental Laboratory (PMEL) of the National Oceanic and Atmospheric Administration (NOAA), also utilizes Paros pressure gauges for the early monitoring of offshore tsunamis over the quasi-global ocean (González et al., 2005).

The HP sensor, based on the quartz pressure transducer of Karrer and Leach (1969), was investigated by Irish 


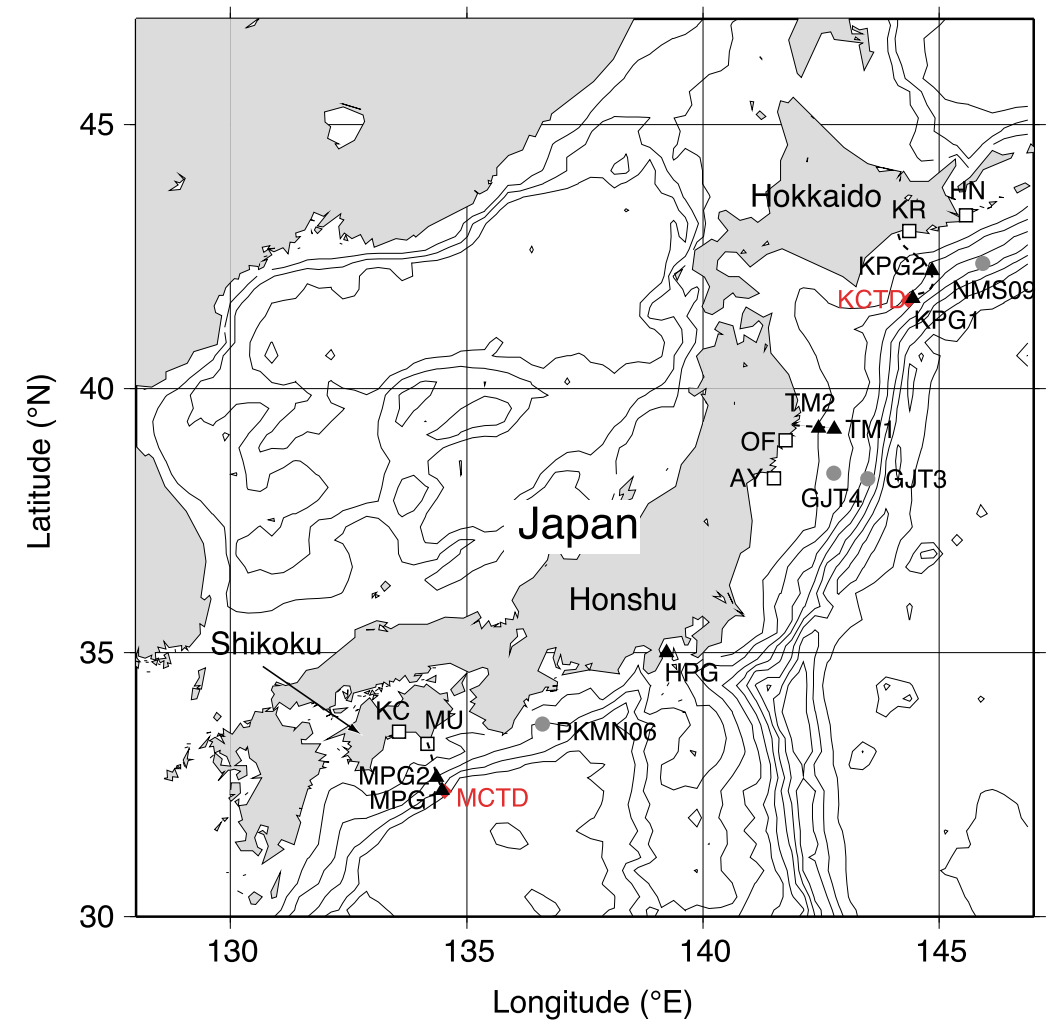

Fig. 1. Sites of OBTMs and a pressure gauge (HPG) deployed on cabled observatories (triangles), autonomous OBP observations conducted by Tohoku University (gray circles), CTDs deployed on the cabled observatories (red diamonds), and tide gauges under JMA (open squares) used in this study.

and Snodgrass (1972), SCOR (1975), Culverhouse (1977), Hayes et al. (1978), and Wearn and Larson (1982). The Japan Meteorological Agency (JMA) has employed a pressure gauge, derived from the HP measurement system, to a real-time observatory cabled from land for monitoring offshore tsunamis and seafloor level changes (Isozaki et al., 1980). Brief descriptions of the cabled observatory have been provided by Isozaki et al. (1980) and Takahashi (1981a, b). Currently, seven cabled observatories utilizing HP pressure gauges around Japan are operated by JMA, the National Research Institute for Earth Science and Disaster Prevention (NIED), the Earthquake Research Institute of the University of Tokyo (ERI), and the Japan Agency for Marine-Earth Science and Technology (JAMSTEC) (Hirata et al., 2009). Although these HP pressure gauges show a fairly good ability to observe tsunamis of the order of millimeters (Hino et al., 2001; Hirata et al., 2003; Baba et al., 2004; Tanioka et al., 2004; Satake et al., 2005; Saito et al., 2010), there have been no reports of successful observations of low-frequency $\left(<1 \mathrm{day}^{-1}\right)$ oceanic variations of the order of centimeters. The HP measurement system possibly has a low detection capability for low-frequency variations. In this paper, pressure gauges, derived from the HP measurement system, deployed on cabled observatories are referred to as ocean bottom tsunami meters (OBTMs) (e.g., Matsumoto et al., 2003; Tsushima et al., 2009).

Baba et al. (2006) detected a large vertical seafloor elevation of tens of centimeters, related to the 2003 Tokachi-oki earthquake $\left(M_{\mathrm{w}} 8.0\right)$, from OBTMs off Kushiro operated by JAMSTEC (Hirata et al., 2002). The detection capability was clearly improved by correcting the OBTM records using a regression coefficient to the temperature changes. Hirata and Baba (2006) estimated a response of OBTM output to transient temperature changes that can cause false pressure signals in the analysis of tsunamis. These supplementary thermal corrections are beyond the routine procedure to calculate the physical pressure value. So far, the dependency of OBTM data on temperature in other frequency bands has not been investigated, and its temporal changes have not been demonstrated. In addition, if an effective correction of OBTM data is possible, it is useful to discuss the detection capabilities of the OBTM data regarding various geophysical phenomena. In this study, the following are investigated: (1) long-term changes, including drifts in the OBTM records, using records of more than ten years; (2) dependency of the OBTM data on temperature in various frequency bands; and (3) the usefulness of the OBTM data for monitoring geophysical phenomena, after a correction based on the estimated relationship between the OBP and temperature in various frequency bands.

\section{Data}

We examine OBP data obtained at six OBTMs deployed on three cabled observatories (Fig. 1). The OBTMs are located at offshore Kamaishi: TM1 and TM2 (Kanazawa and Hasegawa, 1997); Cape Muroto: MPG1 and MPG2 (Momma et al., 1997); and Kushiro: KPG1 and KPG2 (Hirata et al., 2002). OBTM records during periods of more than ten years are used to investigate long-term changes. For reference data to the OBTM data, we use seven sets of OBP data derived from two conductivity-temperaturedepth measuring instruments (CTDs) (MCTD and KCTD) 
Table 1. OBP and tide gauges used in this study.

\begin{tabular}{llccccccc}
\hline Observation & Site & $\begin{array}{c}\text { Latitude } \\
\left({ }^{\circ} \mathrm{N}\right)\end{array}$ & $\begin{array}{c}\text { Longitude } \\
\left({ }^{\circ} \mathrm{E}\right)\end{array}$ & $\begin{array}{c}\text { Depth } \\
(\mathrm{m})\end{array}$ & Sensor & Data period & Sampling & Agency \\
& TM1 & 39.23 & 142.78 & 1563 & HP & Apr. 1997-Dec. 2009 & $10 \mathrm{~Hz}$ & ERI \\
& TM2 & 39.25 & 142.45 & 990 & HP & Apr. 1997-Dec. 2009 & $10 \mathrm{~Hz}$ & ERI \\
Cabled & MPG1 & 32.39 & 134.48 & 2308 & HP & Mar. 1997-Dec. 2009 & $10 \mathrm{~Hz}$ & JAMSTEC \\
OBP & MPG2 & 32.64 & 134.36 & 1507 & HP & Mar. 1997-Dec. 2009 & $10 \mathrm{~Hz}$ & JAMSTEC \\
gauges & MCTD & 32.37 & 134.53 & 3303 & Paros & Jul. 2006-Jun. 2008 & $0.1 \mathrm{~Hz}$ & JAMSTEC \\
& KPG1 & 41.70 & 144.44 & 2218 & HP & Jul. 1999-Dec. 2009 & $10 \mathrm{~Hz}$ & JAMSTEC \\
& KPG2 & 42.24 & 144.85 & 2210 & HP & Jul. 1999-Dec. 2009 & $10 \mathrm{~Hz}$ & JAMSTEC \\
& KCTD & 41.67 & 144.34 & 2540 & Paros & Jul. 2006-Feb. 2010 & $0.1 \mathrm{~Hz}$ & JAMSTEC \\
& HPG & 35.00 & 139.22 & 1176 & Paros & May 2004-Dec. 2009 & $1 \mathrm{~Hz}$ & JAMSTEC \\
Autonomoun & GJT3 & 38.29 & 143.48 & 3321 & Paros & Oct. 2008-Oct. 2009 & $1 \mathrm{~min}$ & Tohoku Univ. \\
OBP & GJT4 & 38.40 & 142.77 & 1450 & Paros & Oct. 2008-Oct. 2009 & $1 \mathrm{~min}$ & Tohoku Univ. \\
gauges & PKMN06 & 33.64 & 136.60 & 2070 & Paros & Aug. 2006-Dec. 2007 & $30 \mathrm{~min}$ & Tohoku Univ. \\
& NMS09 & 42.37 & 145.92 & 3315 & Paros & Jun. 2009-Feb. 2010 & $1 \mathrm{~min}$ & Tohoku Univ. \\
& OF & 39.02 & 141.08 & & & Jan. 2002-Dec. 2009 & $1 \mathrm{hr}$ & JMA \\
& AY & 38.30 & 141.50 & & & Jan. 2002-Dec. 2009 & $1 \mathrm{hr}$ & JMA \\
Tide & MU & 33.27 & 134.17 & & & Jan. 2002-Dec. 2009 & $1 \mathrm{hr}$ & JMA \\
gauges & KC & 33.50 & 133.57 & & & Apr. 2003-Dec. 2009 & $1 \mathrm{hr}$ & JMA \\
& KR & 42.98 & 144.37 & & & Jan. 2002-Dec. 2009 & $1 \mathrm{hr}$ & JMA \\
& HN & 43.28 & 145.57 & & & Jan. 2002-Dec. 2009 & $1 \mathrm{hr}$ & JMA \\
\hline
\end{tabular}

connected to the above-mentioned cabled observatories, one OBP gauge (HPG) connected to a cabled observatory (Iwase et al., 2003), and four autonomous OBP observations (GJT3, GJT4, PKMN06, and NMS09) conducted by Tohoku University. All of the OBP reference data were obtained by the Paros measurement system. Data from six tide gauges are also used for comparison. Details of the data used are listed in Table 1.

In the following sections, we analyze one-minute time series obtained by averaging raw data with a one-minute window and by removing outliers. Ocean tide components in the one-minute OBP time series are removed by applying the NAO.99Jb model (Matsumoto et al., 2000). On the other hand, hourly time series obtained by averaging the one-minute time series with a ten-minute window are used when tidal components are examined.

\section{OBP Records and Remaining Temperature De- pendency}

We have a brief look at OBP data obtained by the HP measurement system in terms of their noise level. Figure 2 shows a comparison between the continuous observations by OBTMs (TM1 and TM2), and autonomous OBP observations (GJT3 and GJT4) using the Paros measurement system. Tidal components are removed by NAO.99Jb. OBP variations of an ocean-data assimilation product, the Estimating the Circulation and Climate of the Ocean run at the Jet Propulsion Laboratory (ECCO-JPL) (e.g., Fukumori et al., 1999; Wunsch et al., 2009), are superimposed on the observations in Fig. 2(a). We can see that the detided OBP variations measured by the Paros pressure gauges and those of the ECCO-JPL model show a good spatio-temporal consistency within at least a $100-\mathrm{km}$ scale. Similar results were also found by Matsumoto et al. (2006). In addition, in the Kuroshio Extension region, Donohue et al. (2010) remarked that OBP variations are spatially consistent within a scale of hundreds of kilometers for periods of 2-30 days.
Since the ECCO-JPL model basically involves only geophysical fluid dynamics, the OBP observations, obtained using the Paros measurement system, have relatively low instrumental noise. However, the OBTM records show a low correlation with the other OBP observations, or the ECCO-JPL model. The variabilities are quite large and appear to be positively correlated with temperature (Fig. 2(b)). The OBTM data thus appear to be affected by temperatureinduced noises relatively more than does the Paros pressure measurement system, at least for periods longer than a few days. These results indicate an insufficiency in the thermal correction calibration of the HP measurement system.

A tidal analysis program, BAYTAP-G, is often used to estimate tides and trends in geophysical time series. The program has a supplementary function designed to correct ambient effects in the time series by referring to concurrently observed data (Ishiguro et al., 1984; Tamura et al., 1991). For example, barometric effects can be well corrected in sea level, strain, and gravimetric data by referring to surface air pressure data at neighboring points. We then use the BAYTAP-G program to examine the OBTM data with, and without, reference to the temperature data (Fig. 3). In the case of referring to the temperature data, the effect of temperature is effectively removed in the OBTM data, more so than in the case without reference to the temperature data; however, discernible temperature effects still remain. The relationship between the OBP and temperature strongly depends on frequency, as will be described in the next section. Since the BAYTAP-G program models the effects of ambient data as an impulse-response function in the whole frequency domain, this approach may not effectively work when the correlation between the OBP and temperature strongly depends on frequency.

We will investigate the temperature dependency of the OBTM data in terms of temporal changes and frequencies in Section 4, and correct the OBTM data using the estimated temperature dependencies in Section 5. 

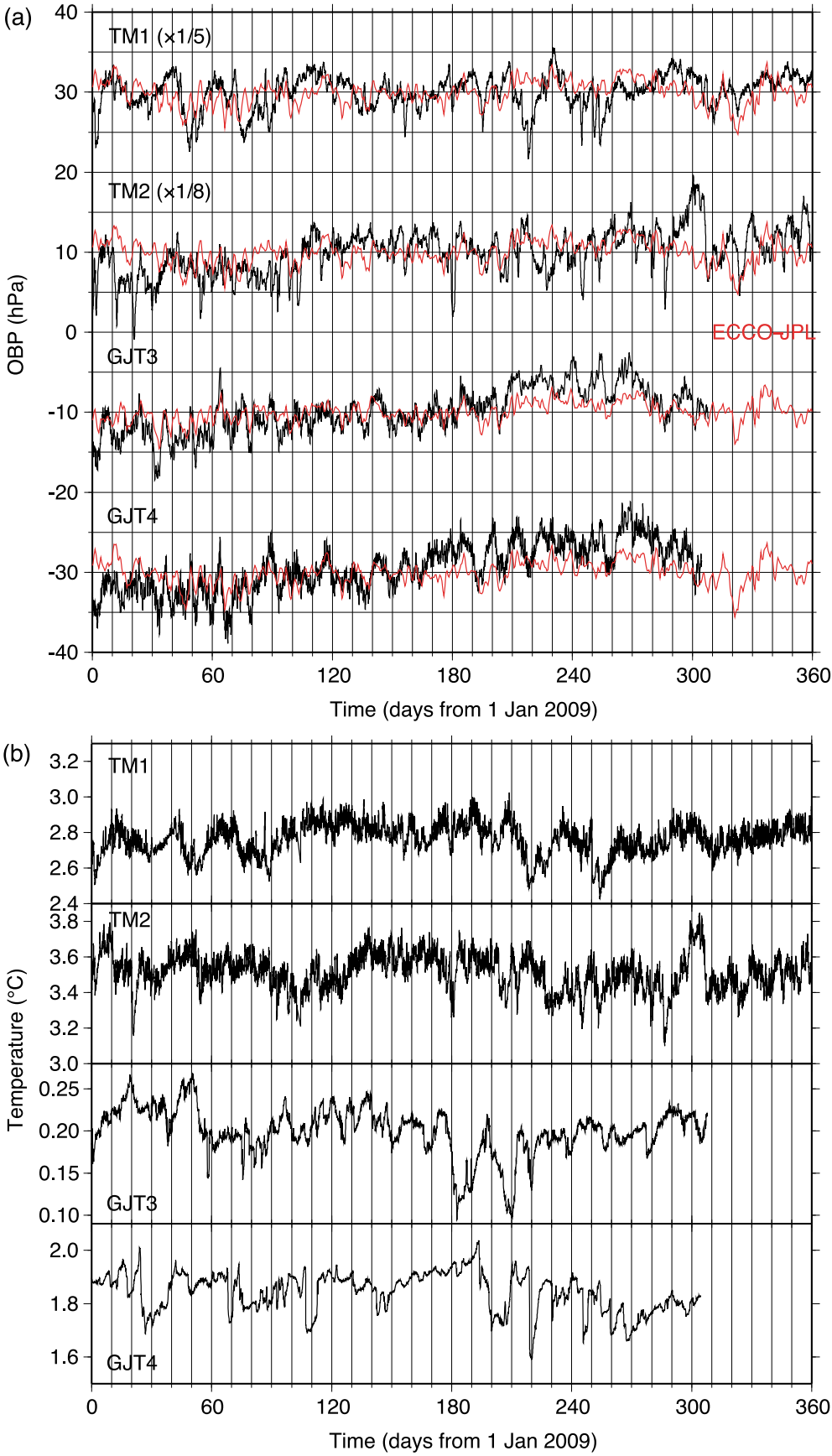

Fig. 2. Records of (a) OBP and (b) built-in thermometers of OBTMs (TM1 and TM2) and of autonomous OBP gauges (GJT3 and GJT4). Black and red lines in (a) are the observations (detided) and the ECCO-JPL model output, respectively. Vertical scales of the observational OBP records of TM1 and TM 2 are reduced by $1 / 5$ and $1 / 8$, respectively.

\section{Lagged Correlation Analysis of the OBTM Data: Relationship between OBP and Temper- ature}

We examine the relationship between the OBP and temperature records obtained by the OBTMs. The detided OBP is compared with the temperature in terms of a regression coefficient and lag. The lag is defined by the maximum positive lagged correlation between the OBP and the temperature, and its sign is defined to be positive when the OBP variation lags behind the temperature. The regression coefficient is calculated based on a least-squares method with the maximum lagged correlation. The analysis is carried out in both the time and frequency domains.

\subsection{Year to year change}

Yearly changes of the calculated regression coefficients, and the lags, are shown in Fig. 4, as well as the temporal evolution of the mean OBP and temperature in each year. The regression coefficients of TM1, TM2, MPG1, and MPG2 clearly show secular increases. A slight increase in the regression coefficient is found for KPG2, while no apparent tendency of the regression coefficient is found for KPG1. The lags of all the OBTMs are 10-100 minutes without temporal changes. The positive lag indicates that the OBTM data show a substantial response to ambient temperature changes with a finite time delay. It appears that each OBTM has a unique regression coefficient and lag, in- 


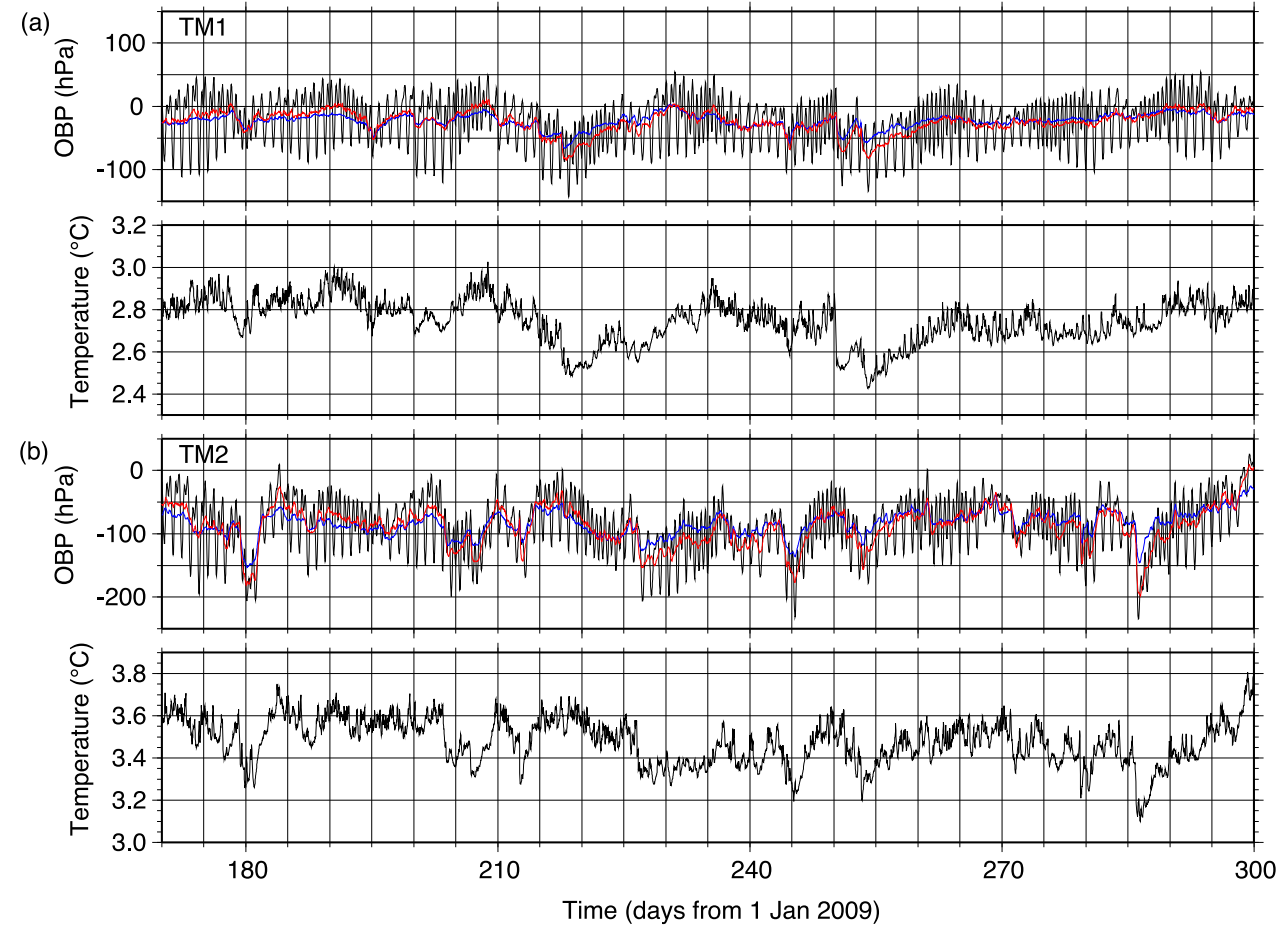

Fig. 3. Time series of OBP and temperature of OBTMs. (a) and (b) denote TM1 and TM2, respectively. Original records (black) and tide-corrected data with (blue) or without (red) referring to the temperature are shown. The OBP shows anomalies from $156400 \mathrm{hPa}$ and $95400 \mathrm{hPa}$ for TM1 and TM2, respectively.

Table 2. Cutoff frequencies for high-pass, band-pass, and low-pass filters. $\omega_{\mathrm{H}}$ and $\omega_{\mathrm{L}}$ are the cutoff frequencies at the high- and low-frequency sides, respectively. Units are hours along time axis.

\begin{tabular}{r|rrrrrrrrrrrrrrrrrr}
\hline$\omega_{\mathrm{H}}$ & 0 & 0 & 0 & 0 & 0 & 0 & 3 & 5 & 11 & 13 & 23 & 27 & 36 & 48 & 48 & 120 & 200 & 300 \\
$\omega_{\mathrm{L}}$ & 0.25 & 0.5 & 1 & 2 & 3 & 4 & 7 & 11 & 13 & 23 & 27 & 48 & 72 & 120 & $\infty$ & $\infty$ & $\infty$ & $\infty$ \\
\hline
\end{tabular}

dicating the extent of the inaccuracy of the calibration of the thermal response of each sensor. These results further indicate that the temperature dependency of the OBTM data has become stronger from year to year. In other words, the OBTM data have become increasingly noisier. It is noted that the increases of the regression coefficients are almost exponential, which may be related to long-term aging of the measurement system.

For TM1, the mean OBP gradually increases at a rate of about $5 \mathrm{hPa} /$ year, while no increase of the mean temperature is evident. Similar results are found for MPG1 and MPG2. The mean OBPs of KPG1 and KPG2 show sudden decreases from 2003 to 2004, corresponding to the coand post-seismic uplift of seafloor due to the 2003 Tokachioki earthquake (Baba et al., 2006). Gradual increases of the mean OBP are nonetheless distinct for the stations before the earthquake. The mean OBP and the mean temperature of TM2 show remarkable changes from 2005 to 2008 : the mean OBP decreases at a rate of $\sim 100 \mathrm{hPa} /$ year, and the bottom temperature decreases at a rate of $0.2^{\circ} \mathrm{C} / \mathrm{year}$ at 1000-m depth without recovery. Since no evidence of vertical seafloor movements (e.g., large earthquake occurrences and/or systematic crustal movements detected by other geodetic measurements) has been reported, it is tentatively concluded that the TM2 data are very unstable and unreliable for studying long-term variations in OBP and temperature. Except for TM2, the mean OBPs show exponential-like increases. The long-term OBP changes seem unrelated to the temperature changes, and are possibly caused by aging due to creep of the pressure-transducer materials (e.g., Eble et al., 1989) and/or burial of the instruments after deployment. Although similar exponential-like temporal changes are also found in the regression coefficients, it is unclear if there is any relationship between the temporal changes in the regression coefficients and those in the mean OBPs.

From the current evaluation, we suggest that these OBTM data point to difficulties in detecting seafloor deformation due to tectonic motions which are expected to show rates of a few cm/year (e.g., Fujita et al., 2006; Matsumoto et al., 2008; Watanabe et al., 2009; Sato et al., 2011). Yearly changes of the mean OBP recorded by the CTDs (Paros measurement system) also show similar long-term changes but their rates are relatively smaller (less than \pm 2 $\mathrm{hPa} /$ year). Drift rates of the Paros OBP data have been investigated and reported to be less than tens of hPa/year (e.g., Watts and Kontoyiannis, 1990; Polster et al., 2009).

\subsection{The relationship depending on frequency}

The relationship between the OBP and temperature was roughly estimated in the previous subsection without con- 
(a)
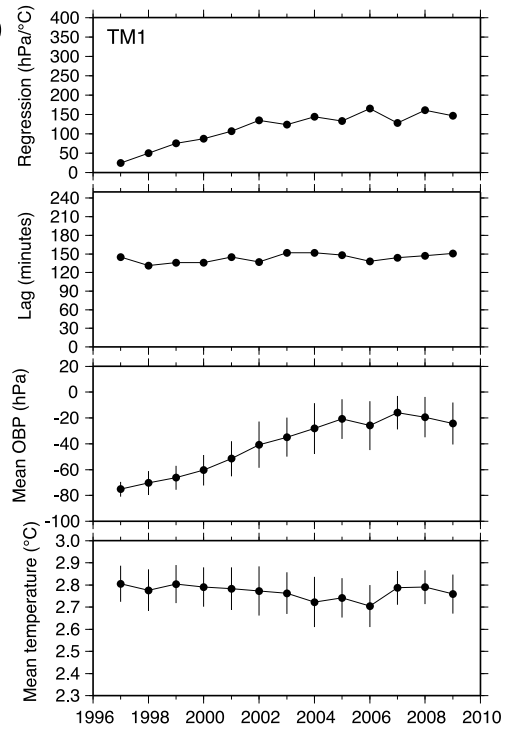

Year

(c)

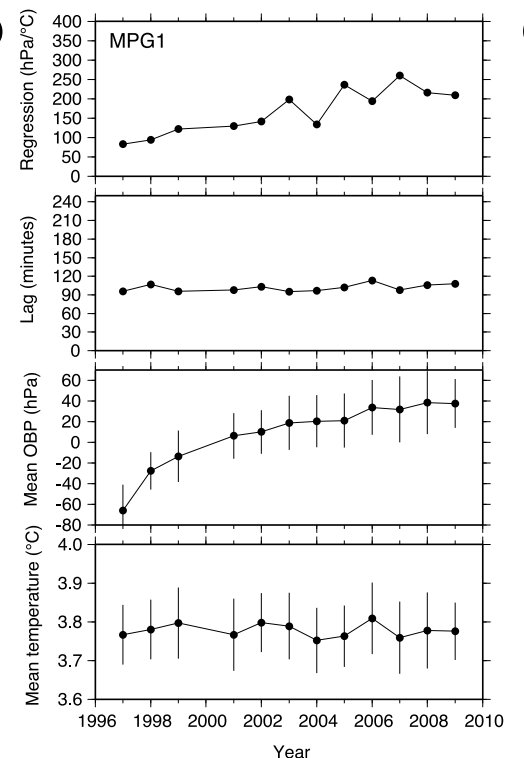

(e)

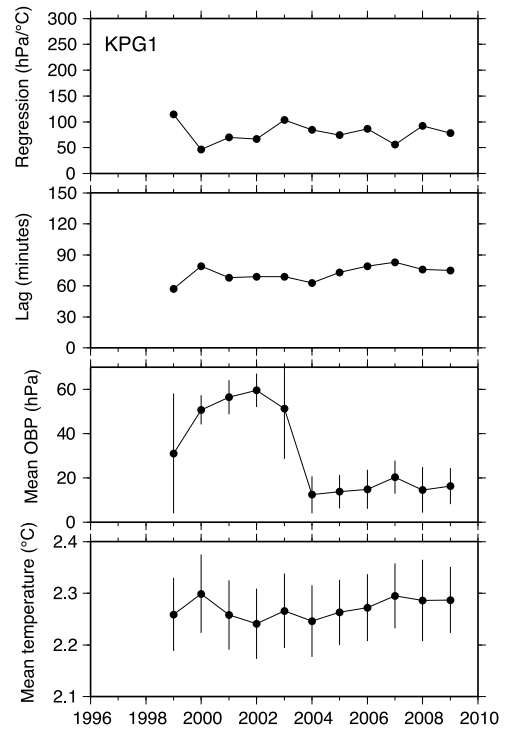

Year
Yeor (b)

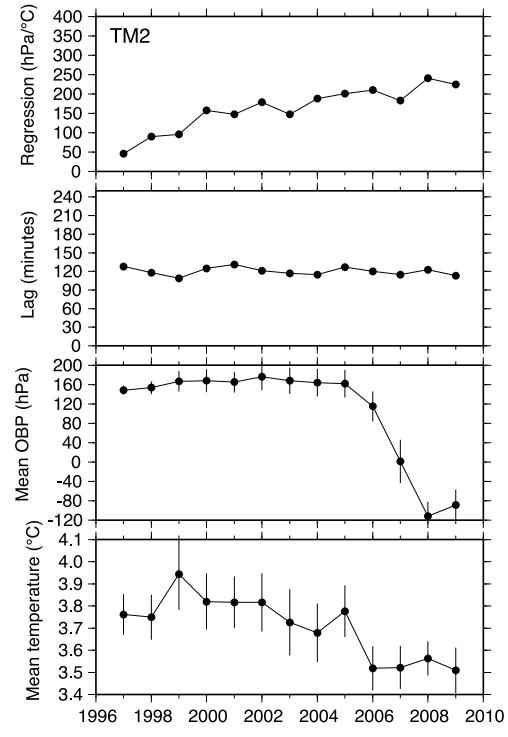

Year

(d)

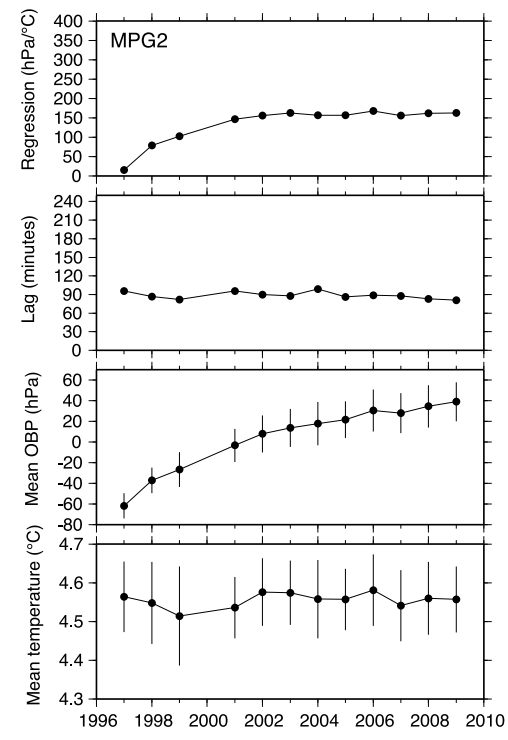

Year

(f)

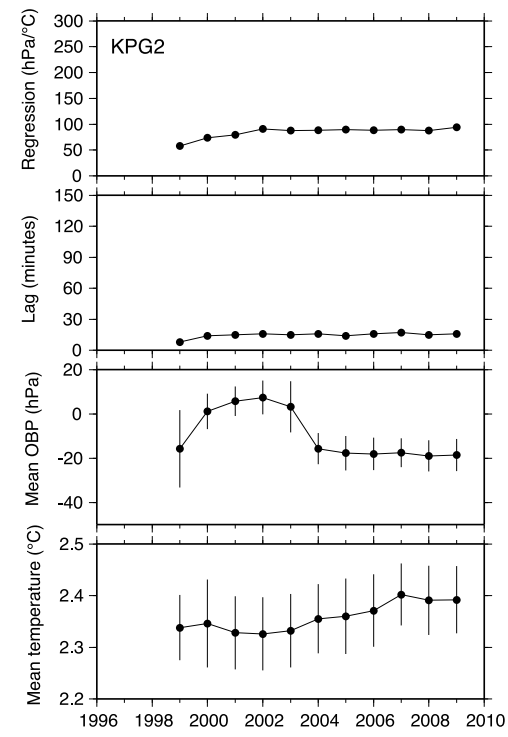

Year

Fig. 4. Yearly changes of regression coefficients, lags, mean OBP, and mean temperature for the six OBTMs. (a) through (f) denote TM1, TM2, MPG1, MPG2, KPG1, and KPG2, respectively. Standard deviations (vertical lines) are attached to the mean OBP and the mean temperature. The mean OBP shows anomalies from a reference depth: TM1 for $156400 \mathrm{hPa}$, TM2 for $95400 \mathrm{hPa}$, MPG1 for $228900 \mathrm{hPa}$, MPG2 for $150700 \mathrm{hPa}$, KPG1 for $222600 \mathrm{hPa}$, and KPG2 for $218100 \mathrm{hPa}$. 

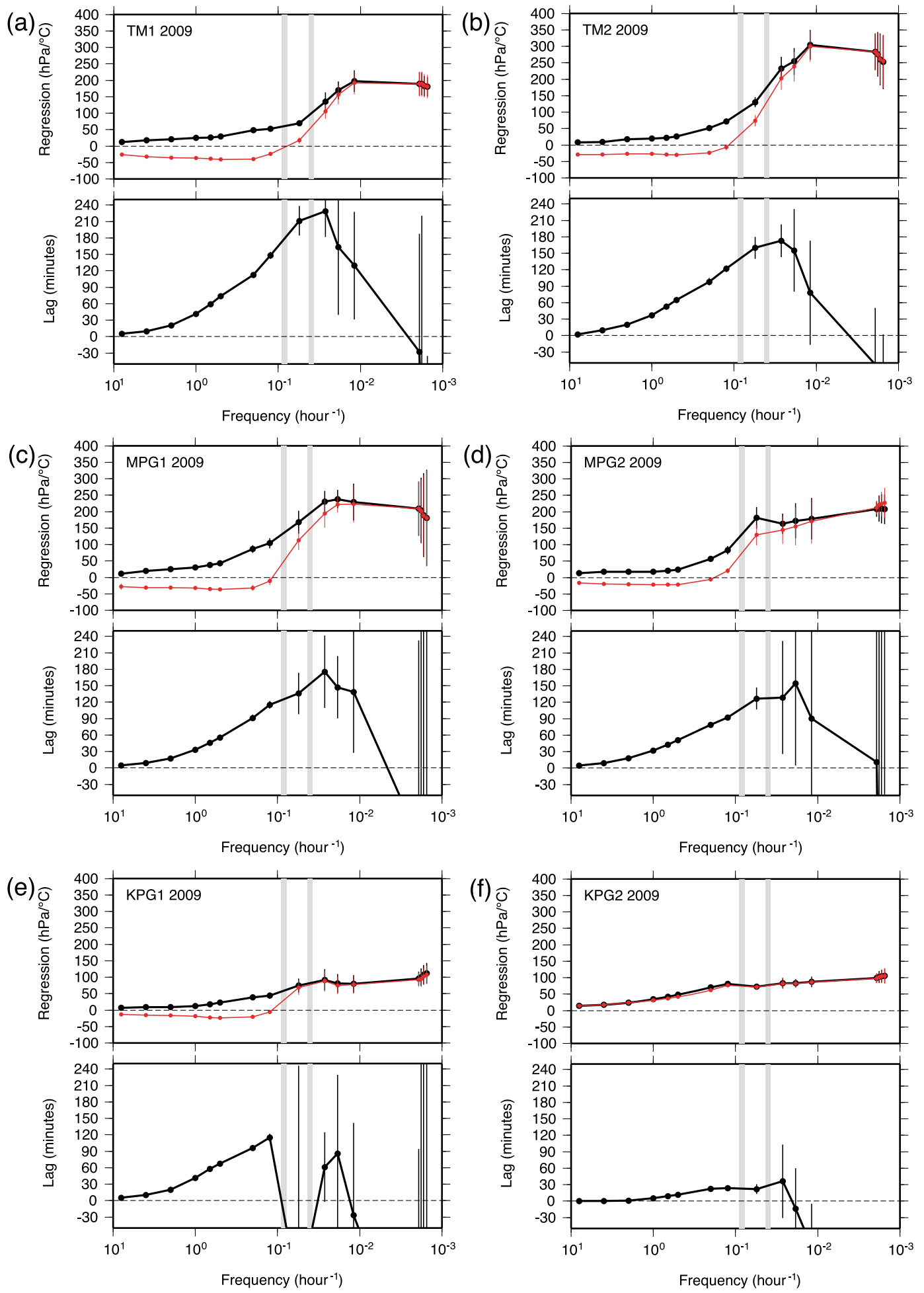

Fig. 5. Regression coefficients and lags as a function of frequency for the six OBTMs. Black lines are the results based on the maximum lagged correlation, and red lines are the regression coefficient in the case assuming zero lag (see text). Error margins (standard deviation) are attached to the estimates. Shaded bands depict tidal frequency bands in which the results are not shown. (a) through (f) denote TM1, TM2, MPG1, MPG2, KPG1, and KPG2, respectively. All the results are from data obtained in 2009.

sidering the dependency on time scales. In this subsection, the relationship is investigated at various frequency bands using high-pass, band-pass, and low-pass non-recursive filters with a Hamming window (Nakamura, 1989). The pass bands employed in this study are listed in Table 2. The OBP and temperature data, filtered for a certain frequency band, are divided into monthly ensembles. The regression coef- ficient and the lag are calculated in the respective monthly ensembles, and their averages from all the ensembles in a year yield the representative values of the regression coefficient and the lag in the corresponding year, at the given frequency band. The relationship for the various frequency bands are calculated for each year.

Figure 5 shows the calculated regression coefficients and 


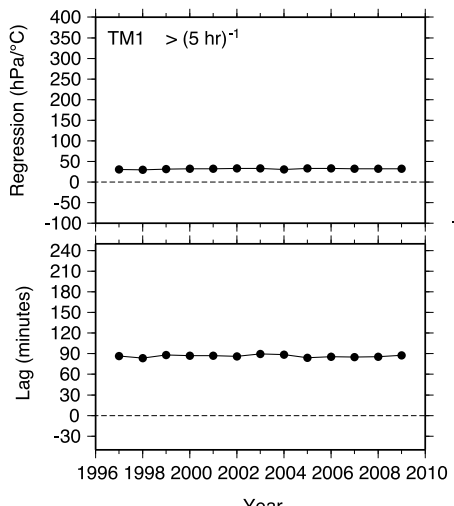

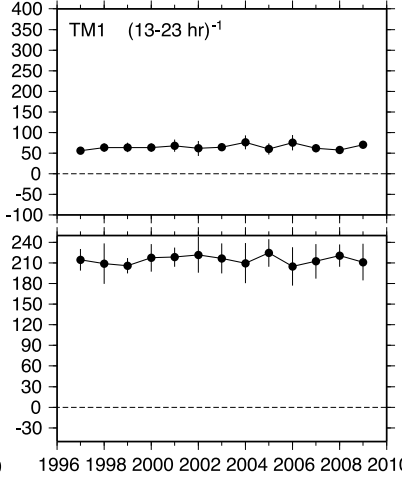

Year
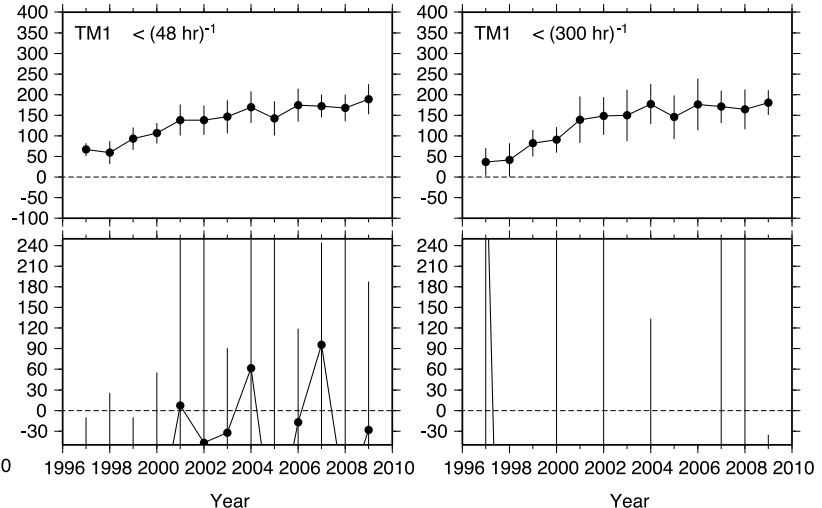

Fig. 6. Yearly changes of regression coefficient and lag of TM1 at selected frequency bands with error margins (standard deviation).

lags of the six OBTMs as a function of frequency in 2009 as an example of the analysis. Both the regression coefficients and the lags show a clear dependency on frequency. At frequencies of higher than 1 hour $^{-1}$, both the regression coefficients and the lags asymptotically approach zero. The regression coefficients and the lags gradually increase at frequencies from $10^{0}$ to $10^{-1}$ hour $^{-1}$. At frequencies lower than $10^{-2}$ hour $^{-1}$, the regression coefficients are almost constant at their maxima, while the lags tend to flip and become negative with large error margins. A negative lag indicates that the temperature changes arise from the OBP changes. An oceanic process related to temperature may cause a negative lag. If the oceanic process involves substantial magnitudes of OBP, the OBP signals originating from temperature changes are identified with difficulty and have large error margins. A possible explanation for the negative lag will be given later.

The regression coefficients estimated at low frequencies $\left(<\sim 1\right.$ day $^{-1}$ ) may not be reliable because the estimated lags have large errors. Here, the regression coefficients are re-estimated assuming that the lag is zero (Fig. 5). At low frequencies, the re-estimated regression coefficients are equivalent to those estimated based on the maximum lagged correlation. So, the actual lags at low frequencies are expected to have maxima of tens to hundreds of minutes for the respective OBTMs. Compared with the periods of several days, the several-hour lags are relatively small in phase dimension. Thus, the regression coefficients are relatively constant at their maxima at low frequencies.

Since long-term increases of the regression coefficients have already been shown in Fig. 4, we consider temporal evolutions of the regression coefficient and the lag, at certain frequency bands (Fig. 6). For the regression coefficient of TM1, it is evident that there is no significant temporal variation at the high-frequency bands, while long-term increases are indicated at the low-frequency bands $(<\sim 1$ $\left.d a y^{-1}\right)$. This feature is common for the other OBTMs. It is unclear why the regression coefficient, i.e., the relationship between the OBP and temperature, becomes interannually stronger at low frequencies.

At tidal frequency bands, the estimation based on the maximum lagged correlation is not robust probably due to remaining ocean tide components. The noise level at the tidal frequency bands will be examined by a tidal analysis

\section{in Section 6.}

We speculate on the cause of the negative lag estimated at the low frequencies $\left(<\sim 1 \mathrm{day}^{-1}\right)$. The negative lag is not expected to originate from the thermal response of the sensor with a finite delay time. At low frequencies, the effects of the thermal response may be relatively negligible compared to substantial oceanic signals. Niiler et al. (1993) remarked that barotropic OBP variations due to water convergence/divergence, with periods of days, are mainly induced by synoptic wind-stress curl fields. For example, water convergence related to a negative wind-stress curl field induces sea-level elevation. This water convergence results in an increase of OBP and a downward movement of water that may contribute to an increase of the bottom temperature, since the temperature of the upper layer is usually warmer than that of the bottom water. This succession could account for the negative lags, i.e. the increase (decrease) of OBP leading the increase (decrease) of the bottom temperature.

\section{Usefulness of the OBTM Data after Tempera- ture Corrections}

In this section, the temperature dependency of the OBTM data are corrected by the regression coefficients and the lags estimated in the previous section (Fig. 5), and the usefulness of the corrected data is examined from a geophysical point of view. At all the frequency bands, the OBTM data are corrected using the regression coefficients and the lags based on the maximum lagged correlation or using the regression coefficients based on the assumption that the lag is zero:

$$
P_{\text {corrected }}(t)=P_{\text {uncorrected }}(t)-r T(t-\tau)
$$

where $r$ and $\tau$ are the regression coefficient and the lag, respectively. $P_{\text {corrected }}(t), P_{\text {uncorrected }}(t)$, and $T(t)$ denote the corrected pressure, uncorrected pressure, and the temperature time series, respectively. Figure 7 shows the amplitudes at the various frequency bands, like a variance-preserving power spectrum, of the corrected and uncorrected OBTM data, and those of the temperature data in 2009. The amplitudes of the Paros OBP data, obtained at the neighboring sites, are also shown for comparison. At low frequencies $\left(<10^{-2}\right.$ hour $\left.^{-1}\right)$, both the corrections yield a reduction in 

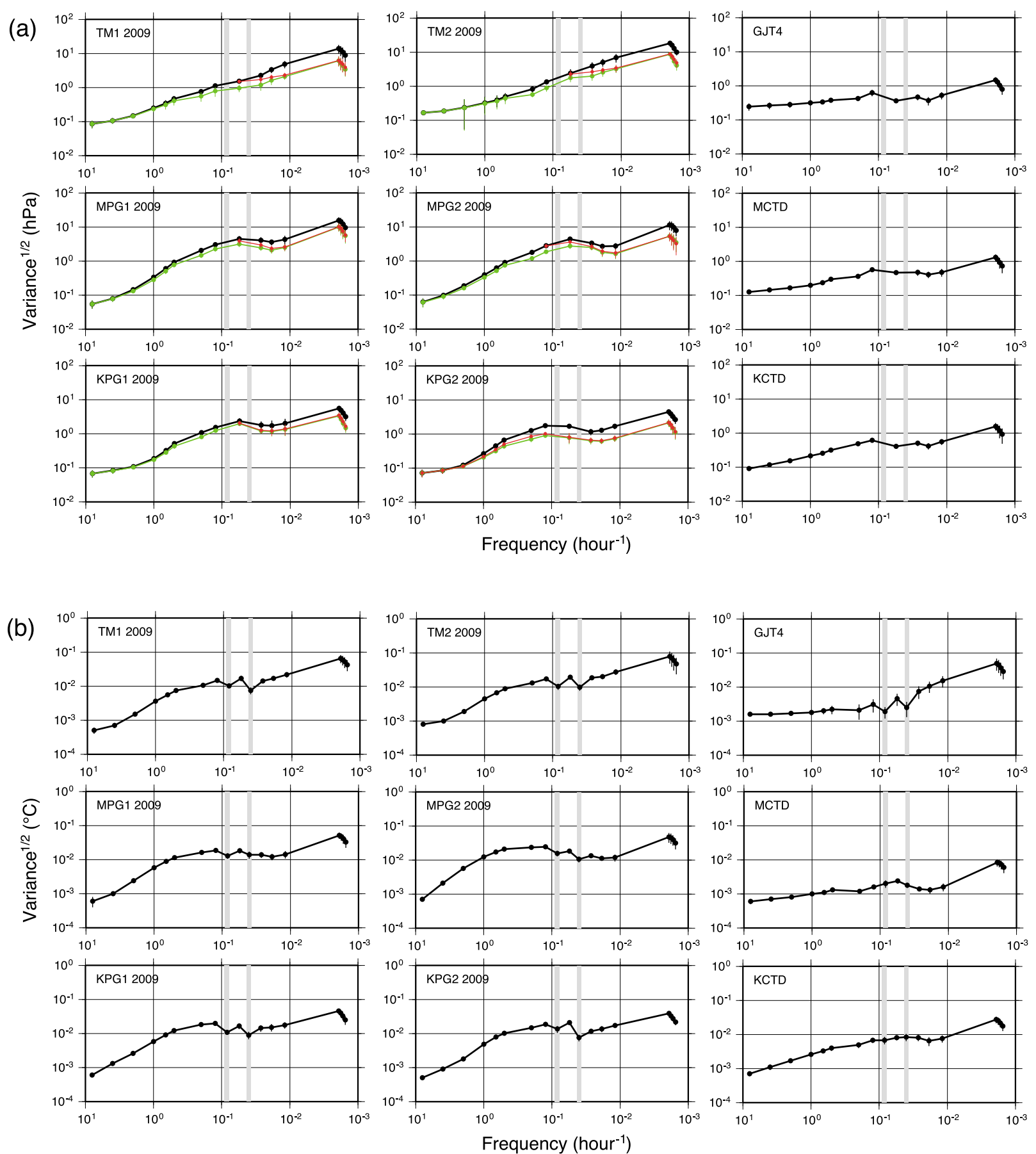

Fig. 7. Amplitudes of (a) OBP and (b) temperature as a function of frequency. Black, green, and red lines are results that are uncorrected, corrected based on the maximum lagged correlation, and corrected based on the assumption that the lag is zero, respectively. The red lines are drawn when the zero-lag regression coefficient is positive. Error margins (standard deviation) are attached to the estimates. Shaded bands depict tidal frequency bands. The results at the tidal frequency bands are not shown in (a). The results are from the data obtained in 2009, except for MCTD for which the data in 2007 is used due to its period of observations (Table 1).

the amplitude of tens of a percent, and therefore the zerolag correction works well in practice. The correction by Baba et al. (2006) is equivalent to the zero-lag correction. At high frequencies $\left(>10^{-2}\right.$ hour $\left.^{-1}\right)$, the correction using the estimated pairs of the regression coefficient and the lag yields a greater reduction in the amplitude than does the zero-lag correction. However, the correction seems largely ineffective at frequencies higher than $10^{0}$ hour $^{-1}$. In the following subsections, we compare the corrected OBTM data with the Paros OBP data within distances of a few hundreds of kilometers from the OBTMs, and evaluate the utility of the OBTM data at low and tsunami frequencies (Fig. 7(a)).

\subsection{Low frequency $\left(<\mathbf{1} \mathrm{day}^{-1}\right)$}

Even after correction, the OBTM data show amplitudes several times greater than those of the Paros OBP data, at frequencies of lower than about $1 \mathrm{day}^{-1}$ for which the correction is expected to be effective. Only the amplitude of the corrected KPG2 data is equivalent to that of the Paros data (KCTD). In Fig. 8, time series from KPG2, KCTD, and NMS09 are compared at frequencies of lower than 0.5 


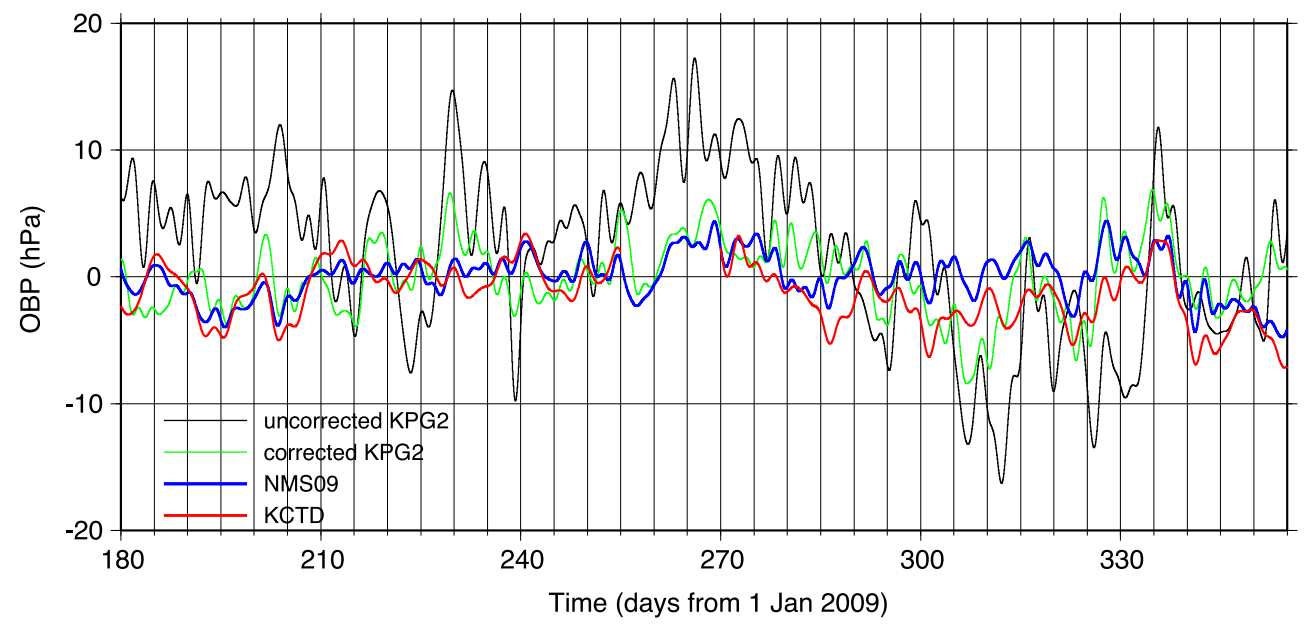

Fig. 8. Time series of uncorrected KPG2 (black), corrected KPG2 with the zero-lag regression coefficient (green), NMS09 (blue), and KCTD (red), respectively, at a frequency of lower than 0.5 day $^{-1}$. The KCTD data include a loss interval around a day of 260 .

Table 3. Results of the correction applied to the OBTM data at the tsunami frequency $\left(>2\right.$ hour $\left.^{-1}\right)$. The results of the overall correction based on the analysis shown in Fig. 7 are also shown at the second line of each OBTM site. Temperature increase and decrease denotes total numbers of the rapid temperature increases and decreases that occurred during the entire observing periods. Numbers in brackets are standard deviations of the estimates. Reduction rates are defined as $\left(1-\frac{\text { corrected SD }}{\text { uncorrected SD }}\right) \times 100$.

\begin{tabular}{|c|c|c|c|c|c|c|}
\hline \multirow{2}{*}{ Site } & \multicolumn{2}{|c|}{ Temperature } & \multirow{2}{*}{$\begin{array}{l}\text { Regression coefficient } \\
\qquad\left(\mathrm{hPa} /{ }^{\circ} \mathrm{C}\right)\end{array}$} & \multirow{2}{*}{$\begin{array}{c}\mathrm{Lag} \\
(\mathrm{min})\end{array}$} & \multirow{2}{*}{$\begin{array}{l}\text { Uncorrected SD } \\
(\mathrm{hPa})\end{array}$} & \multirow{2}{*}{$\begin{array}{c}\text { Reduction rate } \\
(\%)\end{array}$} \\
\hline & Increase & Decrease & & & & \\
\hline \multirow[t]{2}{*}{ TM1 } & 0 & 21 & $15.609(6.120)$ & 10.2 & $0.117(0.031)$ & 5.1 \\
\hline & & & 10.349 & $8.0 \quad(0.9)$ & $0.118 \quad(0.014)$ & 0.8 \\
\hline \multirow[t]{2}{*}{ TM2 } & 3 & 42 & $11.147(6.356)$ & $8.9(4.8)$ & $0.146(0.053)$ & 2.1 \\
\hline & & & $5.774(2.119)$ & $7.6(1.4)$ & $0.133 \quad(0.020)$ & 0.8 \\
\hline \multirow[t]{2}{*}{ MPG1 } & 10 & 469 & $25.352(6.928)$ & 8.9 (4.0) & $0.102(0.048)$ & 6.9 \\
\hline & & & $21.057(2.991)$ & $9.5(0.3)$ & $0.098(0.029)$ & 2.0 \\
\hline \multirow[t]{2}{*}{ MPG2 } & 2037 & 4904 & $18.442(4.114)$ & $9.4(2.4)$ & $0.109(0.092)$ & 10.1 \\
\hline & & & $17.441(1.320)$ & $9.3(0.3)$ & $0.110(0.015)$ & 6.4 \\
\hline \multirow[t]{2}{*}{ KPG1 } & 29 & 441 & $10.381 \quad(2.154)$ & $11.2(5.1)$ & $0.081 \quad(0.033)$ & 3.7 \\
\hline & & & $9.033(0.250)$ & $10.1(0.2)$ & $0.084(0.005)$ & 1.2 \\
\hline \multirow[t]{2}{*}{ KPG2 } & 1 & 31 & $18.286(4.172)$ & $2.1 \quad(5.4)$ & $0.088 \quad(0.027)$ & 5.7 \\
\hline & & & $17.588(1.075)$ & $0.0(0.1)$ & $0.086(0.007)$ & 1.2 \\
\hline
\end{tabular}

SD denotes standard deviation.

day $^{-1}$. Similar variations are found among the Paros data (KCTD and NMS09) and the KPG2 data corrected by the zero-lag regression coefficient. Although the amplitude of the corrected KPG2 data is still a little greater than that of the Paros data, it can be concluded that the corrected KPG2 data enable the successful detection of low-frequency variations (days to weeks) of centimeters caused by oceans, or crustal level changes (e.g., Asano et al., 2008).

\subsection{Tsunami frequency $\left(>2\right.$ hour $\left.^{-1}\right)$}

At frequencies higher than 1 hour $^{-1}$, no significant amplitude reduction in the corrected OBTM data is perceived compared with the uncorrected OBTM data, and the corrected, or uncorrected, OBTM data show noise levels equivalent to those of the Paros data (Fig. 7(a)). So, this overall correction seems ineffective and, therefore, unnecessary at high frequencies. Meanwhile, Hirata and Baba (2006) remarked that the OBTM data should be carefully corrected for the analysis of small tsunamis, since rapid temperature changes (e.g., $\pm 0.005^{\circ} \mathrm{C} / \mathrm{min}$ ) frequently occur. They analyzed the effects of the rapid temperature changes for KPG1 and KPG2 using a convolution method. In the present study, the effectiveness of the correction using the regression method is re-evaluated for a tsunami frequency band when the temperature rapidly changes.

The regression analysis and the correction are performed for individual rapid-temperature-change events rather than the overall time series. The effect of the rapid temperature changes is corrected based on the following three procedures: (1) The rapid-temperature-change events are defined to be occurring when a time derivative in excess of $\pm 0.003^{\circ} \mathrm{C} / \mathrm{min}$ lasts for more than 10 minutes. (2) A frequency of greater than 2 hour $^{-1}$ ( $<30$ minutes) is defined as the tsunami frequency (e.g., Ward, 2001). (3) The regression analysis and the correction are performed on the highpass filtered time series of the OBP and the temperature data during a two-day interval including each rapid-temperaturechange event. A suite of these analyses is carried out for all the OBTM data. Table 3 summarizes the regression analysis and compares this with the results of the overall analysis shown in Fig. 7. First, we consider the temperature varia- 

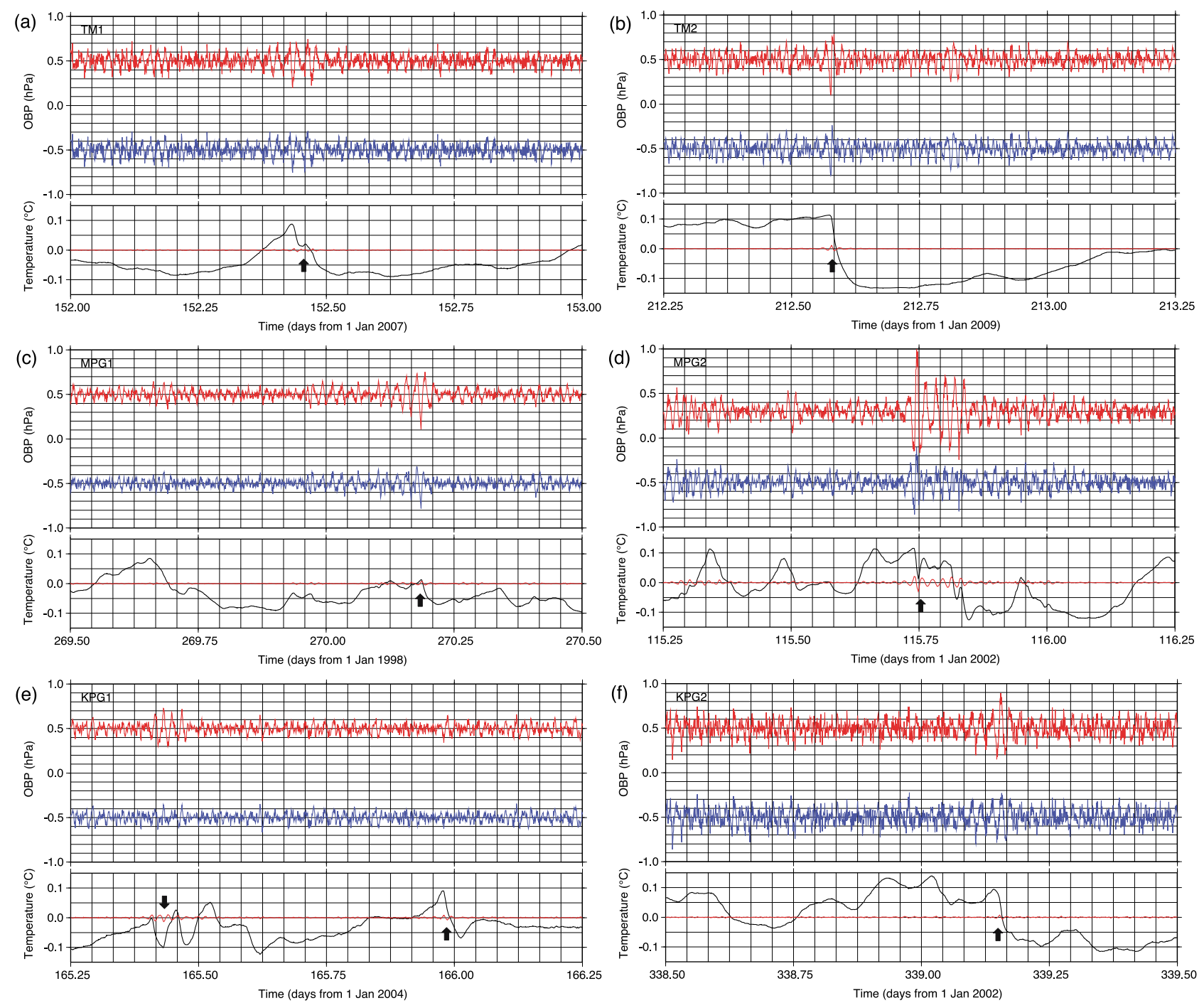

Fig. 9. Time series (JST) of anomalies of OBP and temperature including rapid temperature changes. Red and blue lines are the uncorrected and corrected time series, respectively. The OBP time series are high-pass filtered $\left(>2\right.$ hour $\left.^{-1}\right)$. For the temperature, the filtered and the unfiltered time series are shown. Arrows point the rapid temperature changes. (a) through (f) denote TM1, TM2, MPG1, MPG2, KPG1, and KPG2, respectively.

tions and then indicate the results of the correction.

The rapid temperature changes appear as decreases more frequently than as increases at all the stations. This tendency is probably general, rather than found only at KPG1 and KPG2, as pointed out by Hirata and Baba (2006). It is plausible that cold, dense water penetrates to the sea bottom more easily than does warm, less dense water, after mixing processes near the bottom boundary layer, although the detailed mechanism is poorly understood. Of the six OBTMs, the MPG2 records experience rapid temperature changes most frequently of the order of once a day. This result is anticipated from Fig. 7(b). The MPG2 data show the largest amplitude of temperature variations at the tsunami frequency. In addition, we can see that the variabilities in temperature indeed differ from station to station. The temperature variabilities may be strongly localized by instrument installation: small-scale seafloor undulations (e.g., Hirata and Baba, 2006), depths, seafloor sediments, and the possible burial of sensors.

The correction focusing on rapid-temperature-change events is more effective than the overall correction shown in Fig. 7 (Table 3). Examples of the correction carried out in this subsection appear in Fig. 9. After correction, transient OBP changes related to the rapid temperature changes could be less distinctive with a reduction in amplitude of several millimeters. Since such rapid temperature changes can be accompanied by tsunamis, the OBTM data require to be corrected in order to be meaningful, especially for the MPG2 records (Fig. 10). The results shown above suggest that an easy thermal correction, such as that performed here, is necessary for detailed tsunami analyses.

As shown in Table 3, the regression coefficients and the lags estimated event-by-event are quantitatively equivalent to those based on the overall regression analysis, the results of which are shown in Fig. 5. The regression coefficients calculated here may be a little greater on average than those based on the overall regression analysis, but their differences are within the error margins. The regression coefficients and the lags listed in Table 3 are expected to be useful in practice, not only for tsunami analyses but also in a correction procedure for real-time OBTM data processing to help avoid false tsunami alarms in an early tsunami 

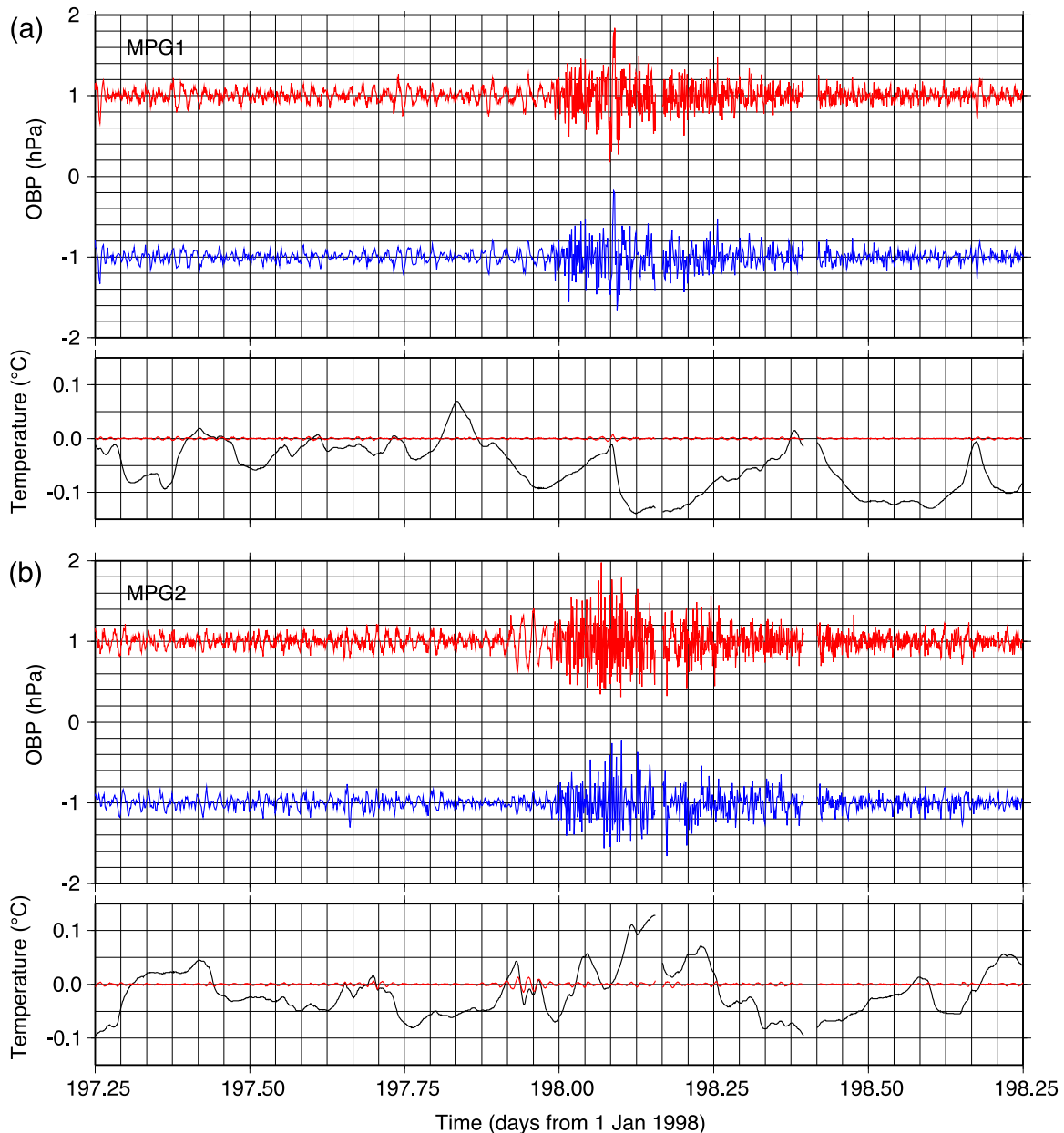

Fig. 10. Time series (JST) of anomalies of OBP and temperature in a case of an observed tsunami generated by the 1998 Papua New Guinea earthquake $\left(M_{\mathrm{w}}\right.$ 7.0). Red and blue lines are the uncorrected and corrected time series, respectively. The OBP time series are high-pass filtered ( $>2$ hour ${ }^{-1}$ ). For the temperature, the filtered and the unfiltered time series are shown. (a) and (b) denote MPG1 and MPG2, respectively. The record was first investigated by Tanioka (1999).

warning system (Tsushima et al., 2009).

\section{Tidal Frequency Bands-Evaluating Seasonal Variations of Tidal Constituents}

We take another approach to assess noise levels of the OBTM data at the tidal frequency bands. At HPG, OBP has been measured by the Paros sensor since May 2004 (Table 1). Monthly variations of four major tidal constituents $\left(\mathrm{M}_{2}, \mathrm{~S}_{2}, \mathrm{~K}_{1}\right.$, and $\left.\mathrm{O}_{1}\right)$ are calculated by the BAYTAP-G program (Fig. 11). A time series of three months is used to calculate the amplitude and phase of the tidal constituents for the middle month. The tidal analysis using the BAYTAP-G program preliminarily calculates equilibrium tides correcting the effect of an 18.6-year nodal modulation (Tamura, 1987). We can note pronounced seasonal variations of the tidal constituents rather than interannual variations. The range of the seasonal variations is of the order of $1 \mathrm{hPa}$ for amplitude and 1 degree for phase.

Seasonal variations of ocean tides have been reported in terms of sea level by a number of studies (e.g., Tamura, 1985; Pugh, 1987; Kang et al., 1995, 2002; Leeuwenburgh et al., 1999; Blanton et al., 2004) and, in spite of limited studies, in terms of OBP (e.g., Tamura et al., 1986; Blanton et al., 2004). Tamura et al. (1986) used the OBTM data of
JMA (Isozaki et al., 1980) and pointed to a seasonal variation of the $\mathrm{M}_{2}$ constituent, without detailed discussions. Blanton et al. (2004) used sea level and OBP data, and noted a seasonal variation of the $\mathrm{M}_{2}$ constituent of the sea level, but hardly described the seasonal variation of the OBP tide because of the short duration of the observations. Although the effects of stratification (Kang et al., 2002) and tide-surge interaction (e.g., Pugh, 1987; Leeuwenburgh et al., 1999; Bernier and Thompson, 2007) have been suggested as causes of the seasonal variation of ocean tides in coastal regions, critical mechanisms have not yet been proposed (Woodworth, 2010). Although, investigating the mechanism of the seasonal modulation of ocean tides is beyond the scope of the present study, we assume that the seasonal variations of the OBP tide should be observed ubiquitously and their detectability is regarded as a measure of the quality of the OBP data at the tidal frequency bands.

Monthly variations of the OBP tide are shown for TM1, TM2, GJT3, and GJT4 (Fig. 12(a)). The variations of GJT3 and GJT4 are quite similar to each other even though the data periods are only fifteen months. It is likely that the OBP tide shows the seasonal variation with its spatial correlation within at least $100 \mathrm{~km}$. Such spatial correlations are also found from the seasonal variations in the sea level 


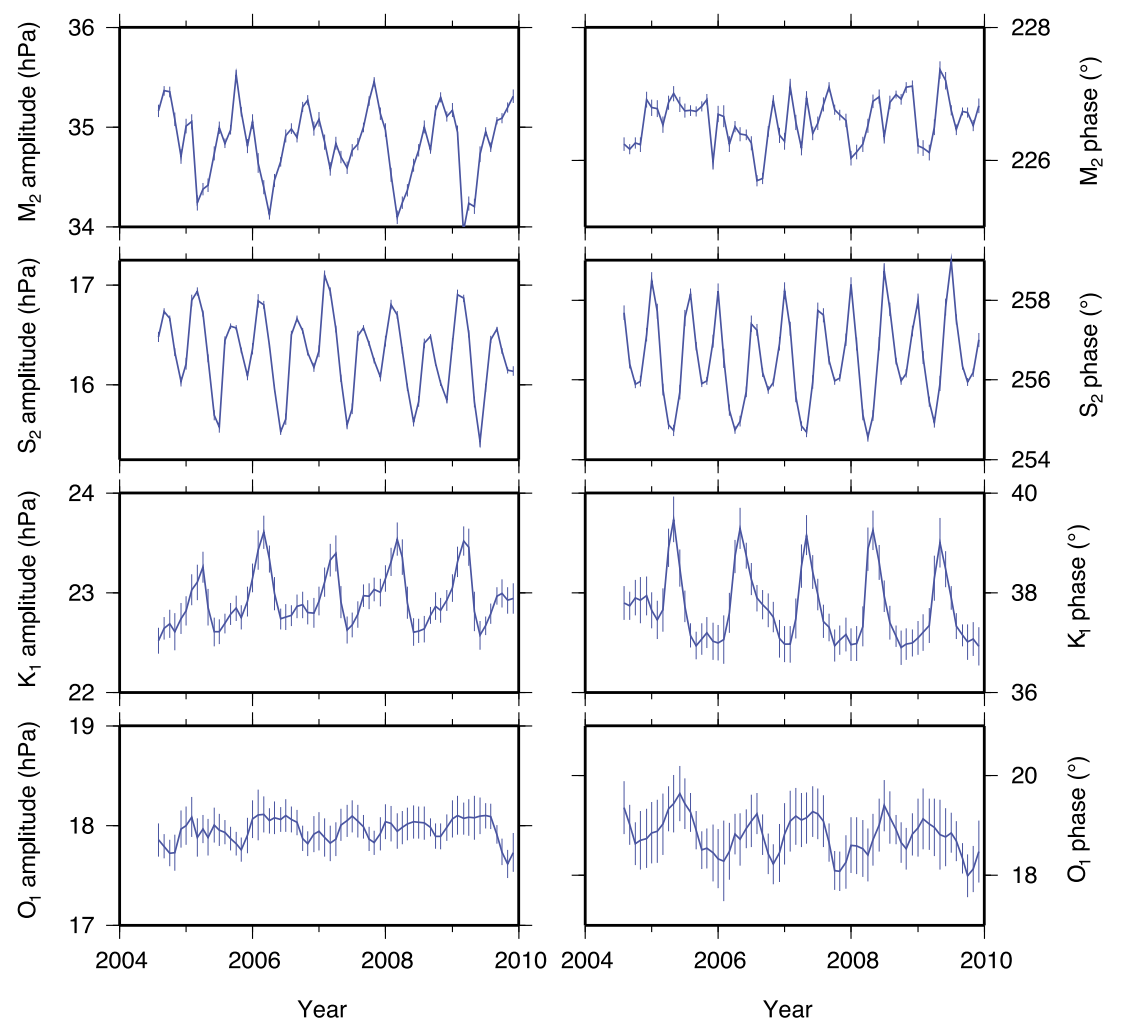

Fig. 11. Monthly variations of four major tidal constituents with error margins calculated from the HPG data.

tides (Table 4). Thus, the seasonal variations of OBP tides of both TM1 and TM2 are expected to agree with those of GJT3 and GJT4. The result of TM1 shows better agreement with GJT3 and GJT4 than that of TM2. TM1 is probably less noisy than TM2 at the tidal frequency bands. Similar comparisons have been carried out for MPG1, MPG2, KPG1 and KPG2 (Fig. 12(b) and Table 4). As a result, the KPG2 data, as well as the TM1 data, are expected to successfully detect the seasonal variations of OBP tides, but the other data are probably not.

We perform another evaluation of temperature-dependent noises in the OBTM data at the tidal frequency bands. The regression coefficients and the amplitudes of the temperature variation at the semi-diurnal (11-13 hours) and diurnal (23-27 hours) bands are shown in Figs. 5 and 7. The product of the regression coefficient and the temperature amplitude can be regarded as a proxy of the temperaturedependent noise at the tidal frequency bands (Fig. 13). As is expected, TM1 and KPG2 show relatively low noises $(<1$ $\mathrm{hPa})$. The others include higher noises $(>1.5 \mathrm{hPa})$ and 1$\mathrm{hPa}$ variations of tidal constituents are difficult to detect. Although the expected noise level of KPG1 is as low as that of KPG2, the result of the tidal analysis (Fig. 12(b) and Table 4 ) indicates that the estimated variation of the tidal constituents of KPG1 is unstable and insufficient for analyses of $1-\mathrm{hPa}$ seasonal variations.

\section{Summary}

We investigated the six OBTM data that include significant dependency on the change of the built-in thermometer output. The OBTM data show spurious signals which are positively correlated with the temperature and lag behind the temperature by tens of minutes. In the present study, this relationship was characterized by the regression coefficient and the lag between the OBP and the temperature. The relationship depends on frequency, and becomes stronger at periods from hours to days. The relationship at frequencies lower than $\sim 1$ day $^{-1}$ secularly becomes strong. These relationships differ from station to station. The yearly mean OBPs gradually increase at rates of the order of $1 \mathrm{hPa} / y e a r$, possibly due to aging of the measurement system. Thus the OBTM data involve difficulties in detecting seafloor deformation due to tectonic motions.

The OBTM data were corrected based on the estimated relationship. The usefulness of the corrected OBTM data was evaluated by comparison to the Paros OBP data which have relatively low instrumental noises. At frequencies of lower than $\sim 1$ day $^{-1}$, the corrected data show a reduction in amplitude of the order of a few tens of a percent, but are several times noisier than the Paros data. Only the corrected KPG2 data show amplitudes almost equivalent to that of the Paros data, and could be useful for detecting several-centimeter variations of the ocean, and seafloor deformation, at low frequencies. At frequencies higher than 1 hour $^{-1}$, the noise levels of the OBTM data were found to be equivalent to those of the Paros data, without the correction. At a tsunami frequency range ( $>2$ hour $^{-1}$ ), however, rapid temperature changes in excess of $\pm 0.003^{\circ} \mathrm{C} / \mathrm{min}$ frequently occur, resulting in spurious signals in the OBTM records. The rapid temperature changes occur typically as decreases in temperature. Focusing on the rapid temperature changes, the effectiveness of the correction was re-evaluated, and noise related to the temperature can be reduced by millimeters. We need to carefully ana- 
(a)

TM1 - TM2
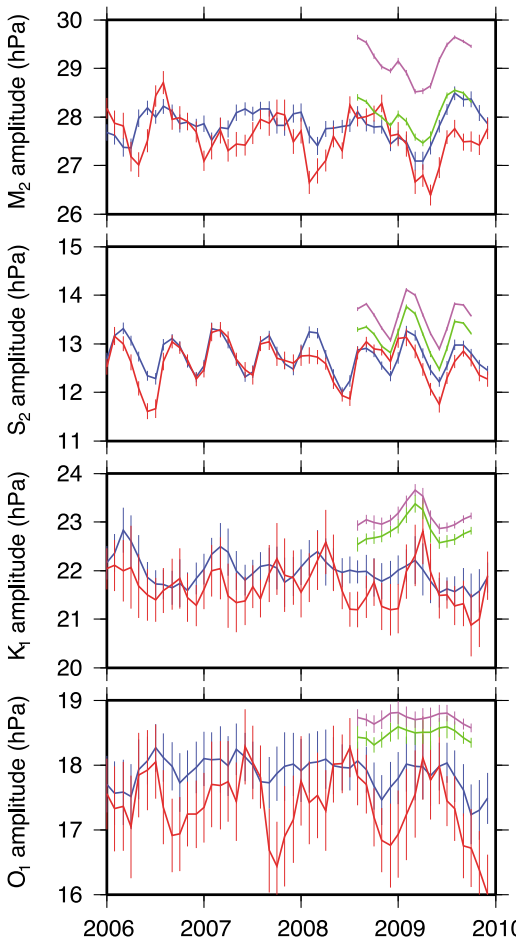

Year

(b)
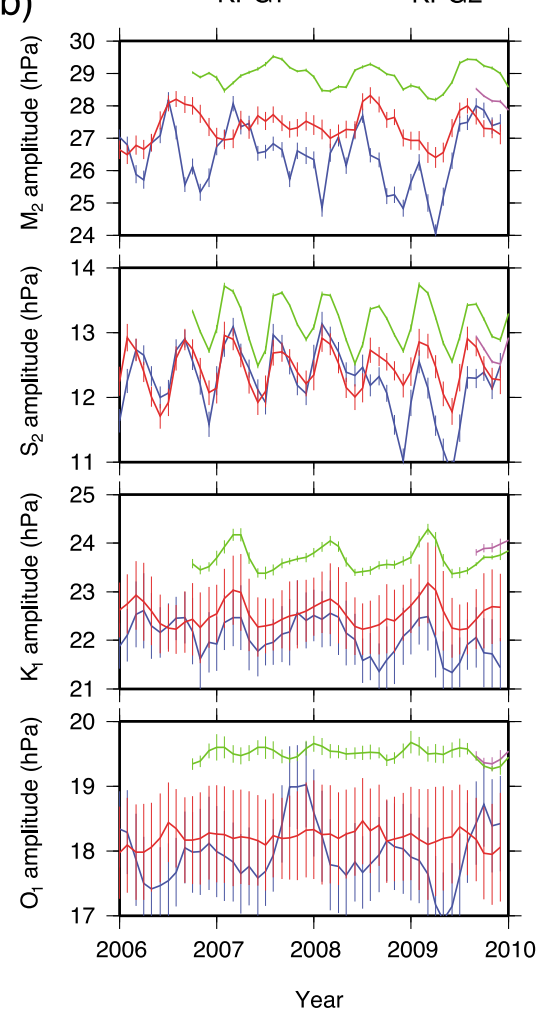

$\longrightarrow$ GJT3 $\quad$ GJT4
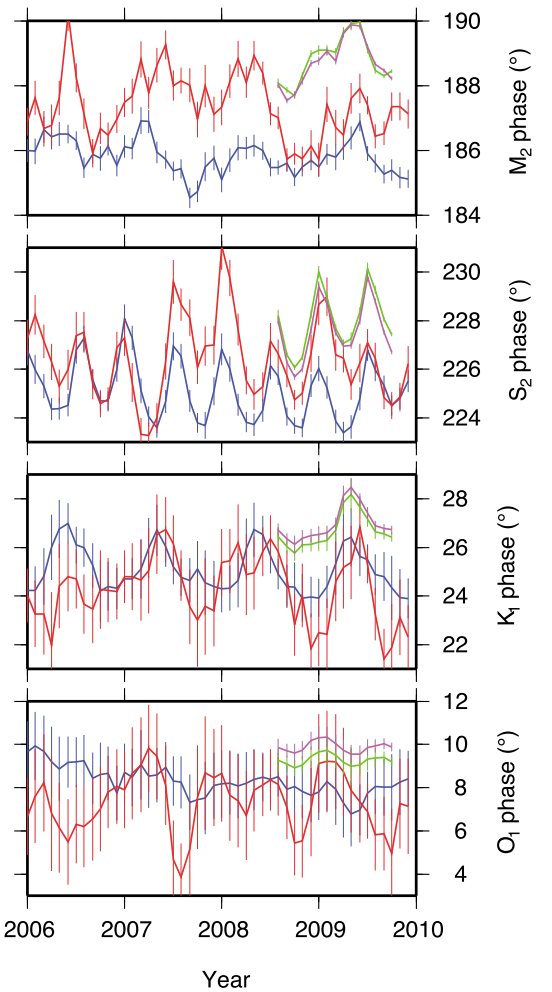

Year
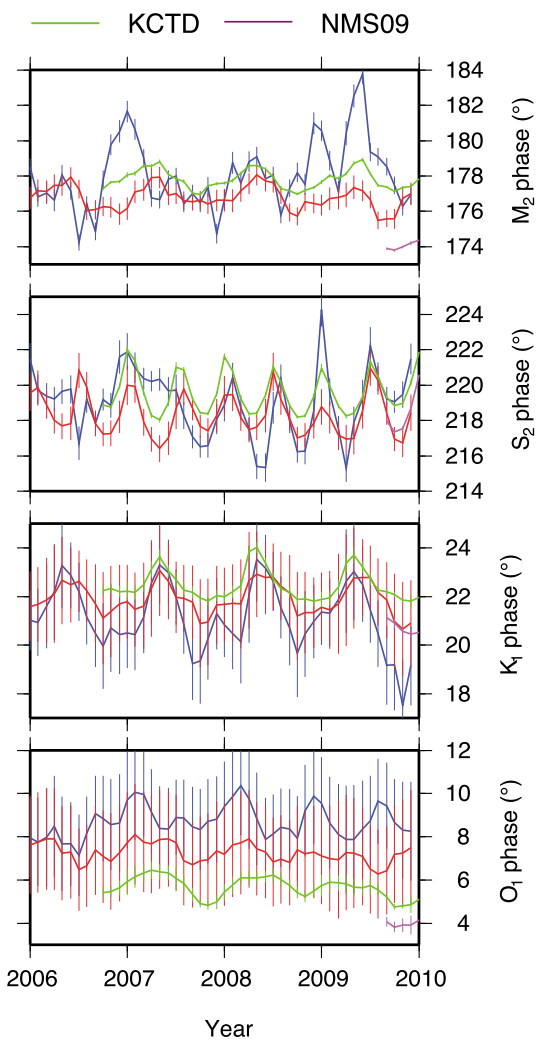

Fig. 12. Monthly variations of four major tidal constituents with error margins calculated from the OBP data (a) off Kamaishi and (b) off Kushiro. In (a), blue, red, green, and purple lines are TM1, TM2, GJT3, and GJT4, respectively. In (b), blue, red, green, and purple lines are KPG1, KPG2, KCTD, and NMS09, respectively.

lyze tsunamis in OBTM records by correcting the effects of rapid temperature changes, especially for the MPG2 data in which a number of rapid temperature changes occur.

A correction for tidal frequency bands has not been pro- posed in this study. However, tidal analyses have suggested that the TM1 and KPG2 data could be used to study temporal variations of tidal constituents in excess of $1 \mathrm{hPa}$, even though they are a little noisier than the Paros data. The tidal 
Table 4. Correlation coefficients of monthly variations of tidal constituents calculated from a pair of neighboring stations. The correlation coefficient is calculated by weighting the amplitude of four major tidal constituents $\left(\mathrm{M}_{2}, \mathrm{~S}_{2}, \mathrm{~K}_{1}\right.$, and $\left.\mathrm{O}_{1}\right)$. The correlation coefficients in excess of a $99.5 \%$ confidence level are marked. The correlation coefficient between KCTD and NMS09 is blank due to the short data length.

\begin{tabular}{llccc}
\hline & Sites & $\begin{array}{c}\text { Data } \\
\text { number }\end{array}$ & $\begin{array}{c}\text { Correlation } \\
\text { coefficient }\end{array}$ & $\begin{array}{c}99.5 \% \\
\text { confidence level }\end{array}$ \\
\hline OF & AY & 94 & 0.66 & x \\
MU & KC & 74 & 0.60 & x \\
KR & HN & 94 & 0.48 & x \\
& & & & \\
GJT3 & GJT4 & 15 & 0.96 & x \\
GJT3 & TM1 & 15 & 0.78 & x \\
GJT3 & TM2 & 15 & 0.60 & \\
& & & & \\
MCTD & PKMN06 & 13 & 0.77 & x \\
MCTD & MPG1 & 20 & 0.25 & \\
MCTD & MPG2 & 20 & 0.26 & \\
& & & & \\
KCTD & NMS09 & 6 & - & \\
KCTD & KPG1 & 39 & 0.46 & \\
KCTD & KPG2 & 39 & 0.76 & x \\
\hline
\end{tabular}
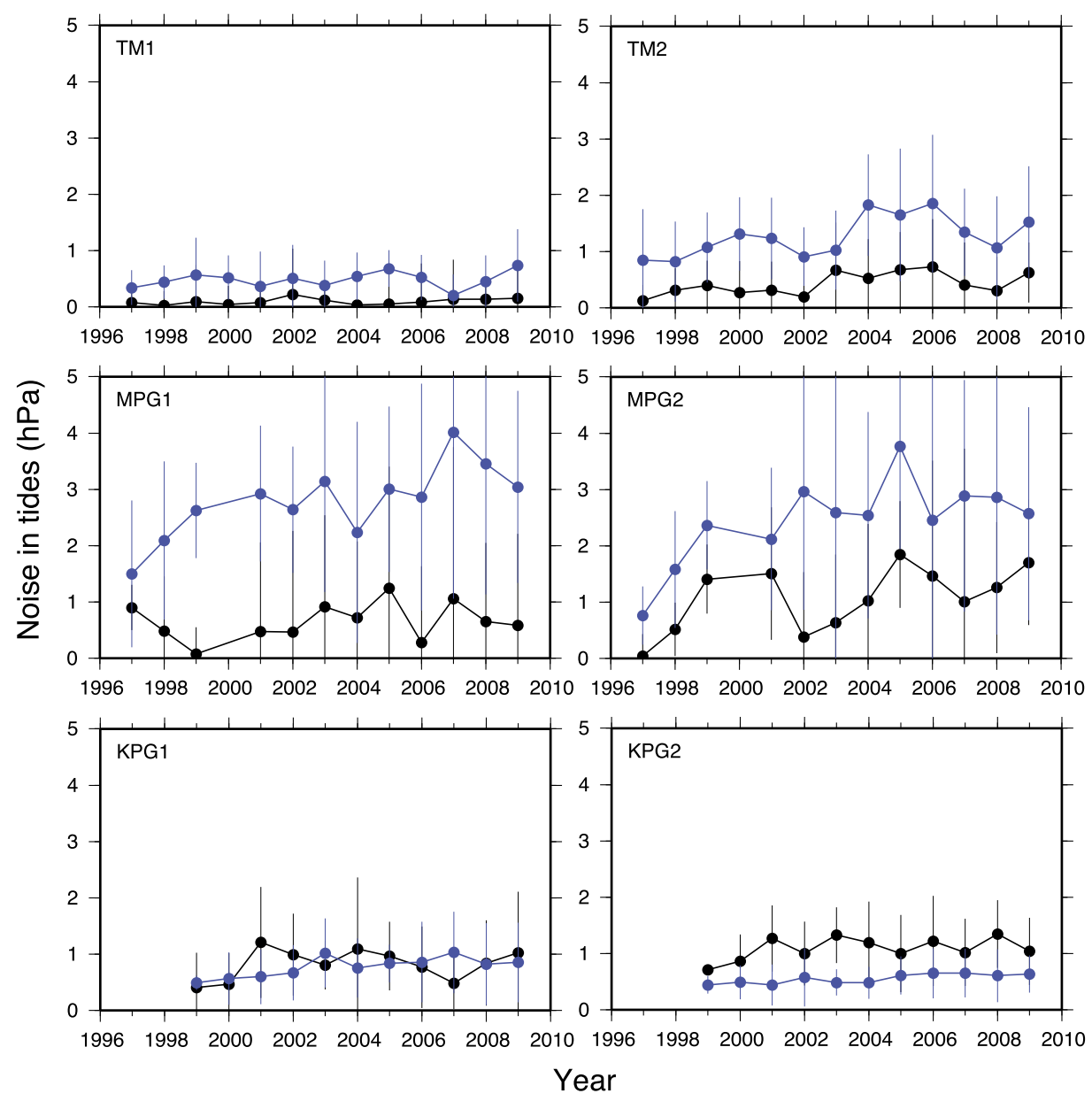

Fig. 13. Time evolutions of estimated noise level with error margins at tidal frequency bands of the six OBTMs. Black and blue lines indicate the results at semi-diurnal and diurnal bands, respectively.

constituents are known to change seasonally (e.g., Kang et al., 2002), interannually (e.g., Munk et al., 1965), and secularly (e.g., Ray, 2006, and references therein) although their mechanisms are still poorly understood. Even the theoretically expected 18.6-year nodal modulation has recently been paid attention in relation to bi-decadal climate changes (e.g., Osafune and Yasuda, 2006; Ray, 2007). It is expected that such OBTM data in excess of 10-year durations will yield valuable information for tidal studies.

Similar investigations of other OBTM data from the ca- 
bled systems around Japan (see Hirata et al., 2009) will be awaited in order to examine their potential applicability to oceanography and geodesy, as well as seismology. In addition, the recent cabled systems of HPG, other CTDs, and the Dense Oceanfloor Network System for Earthquakes and Tsunamis (DONET) (Araki et al., 2008) using the Paros sensors, as well as the DART system, are expected to be of use in a wide range geophysical applications.

Acknowledgments. We thank Ichiro Takahashi and Toshitaka Baba of JAMSTEC for kindly providing the data obtained from the cabled systems operated by JAMSTEC, and Hiromi Fujimoto and Yukihito Osada of Tohoku University for providing the OBP data obtained from their observations. Hiroaki Tsushima of MRI/JMA (Meteorological Research Institute) and Syuichi Suzuki of Tohoku University helped for handling the OBTM data operated by ERI. We also thank JMA for the presentation of the tide gauge data. The author, Daisuke Inazu, thanks Tadahiro Sato of Tohoku University for gracious discussions on tidal analyses. Comments and suggestions from William W. Chadwick Jr. and an anonymous reviewer improved this presentation. This study was funded by a MEXT (Ministry of Education, Culture, Sports, Science and Technology of Japan) project entitled "Research concerning Interaction between the Tokai, Tonankai and Nankai Earthquakes". All the figures in this paper were produced using Generic Mapping Tools.

\section{References}

Araki, E., K. Kawaguchi, S. Kaneko, and Y. Kaneda, Design of deep ocean submarine cable observation network for earthquakes and tsunamis, Proc. Ocean 2008 Mar. Technol. Soc. IEEE Techno-Ocean, 1-4, 2008.

Asano, Y., K. Obara, and Y. Ito, Spatiotemporal distribution of very-low frequency earthquakes in Tokachi-oki near the junction of the Kuril and Japan trenches revealed by using array signal processing, Earth Planets Space, 60, 871-875, 2008.

Baba, T., K. Hirata, and Y. Kaneda, Tsunami magnitudes determined from ocean-bottom pressure gauge data around Japan, Geophys. Res. Lett., 31, L08303, doi:10.1029/2003GL019397, 2004.

Baba, T., K. Hirata, T. Hori, and H. Sakaguchi, Offshore geodetic data conducive to the estimation of the afterslip distribution following the 2003 Tokachi-oki earthquake, Earth Planet. Sci. Lett., 241, 281-292, 2006.

Bernier, N. B. and K. R. Thompson, Tide-surge interaction off the east coast of Canada and northeastern United States, J. Geophys. Res.Oceans, 112, C06008, doi:10.1029/2006JC003793, 2007.

Blanton, B. O., F. E. Werner, H. E. Seim, R. A. Luettich, Jr., D. R. Lynch, K. W. Smith, G. Voulgaris, F. M. Bingham, and F. Way, Barotropic tides in the South Atlantic Bight, J. Geophys. Res.-Oceans, 109, C12024, doi:10.1029/2004JC002455, 2004.

Chadwick Jr., W. W., S. L. Nooner, M. A. Zumberge, R. W. Embley, and C. G. Fox, Vertical deformation monitoring at Axial Seamount since its 1998 eruption using deep-sea pressure sensors, J. Volcanol. Geotherm. Res., 150, 313-327, 2006.

Culverhouse, B., Self-contained digital tide measurement system, NOAA Tech. Memo. ERL AOML-24, 47 pp., 1977.

Donohue, K. A., D. R. Watts, K. L. Tracey, A. D. Greene, and M. Kennelly, Mapping circulation in the Kuroshio Extension with an array of current and pressure recording inverted echo sounders, J. Atmos. Oceanic Technol., 27, 507-527, 2010.

Eble, M. C., F. I. González, D. M. Mattens, and H. B. Milburn, Instrumentation, field operations, and data processing for PMEL deep ocean bottom pressure measurements, NOAA Tech. Memo. ERL PMEL-89, 71 pp., 1989.

Filloux, J. H., Deep-sea tide gauge with optical readout of bourdon tube rotations, Nature, 226, 935-937, 1970.

Filloux, J. H., Tsunami recorded on the open ocean floor, Geophys. Res. Lett., 9, 25-28, 1982.

Fox, C. G., Evidence of active ground deformation on the mid-ocean ridge: Axial Seamount, Juan de Fuca Ridge, April-June 1988, J. Geophys. Res.-Solid Earth, 95, 12813-12822, 1990.

Fujimoto, H., M. Mochizuki, K. Mitsuzawa, T. Tamaki, and T. Sato, Ocean bottom pressure variations in the southeastern Pacific following the 1997-98 El Niño event, Geophys. Res. Lett., 30, 1456,
doi:10.1029/2002GL016677, 2003.

Fujita, M., T. Ishikawa, M. Mochizuki, M. Sato, S. Toyama, M. Katayama, K. Kawai, Y. Matsumoto, T. Yabuki, A. Asada, and O. L. Colombo, GPS/Acoustic seafloor geodetic observation: method of data analysis and its application, Earth Planets Space, 58, 265-275, 2006.

Fukumori, I., R. Raghunath, L.-L. Fu, and Y. Chao, Assimilation of TOPEX/Poseidon altimeter data into a global ocean circulation model: How good are the results?, J. Geophys. Res.-Oceans, 104, 2564725665, 1999.

González, F. I., E. N. Bernard, C. Meinig, M. C. Eble, H. O. Mofjeld, and S. Stalin, The NTHMP tsunameter network, Nat. Hazards, 35, 25-39, 2005.

Hayes, S. P., J. Glenn, and N. N. Sriede, A shallow water pressuretemperature gauge (PTG): Design, calibration, and operation, NOAA Tech. Memo. ERL PMEL-12, 31 pp., 1978.

Hino, R., Y. Tanioka, T. Kanazawa, S. Sakai, M. Nishino, and K. Suyehiro, Micro-tsunami from a local interplate earthquake detected by cabled offshore tsunami observation in northeastern Japan, Geophys. Res. Lett., 28, 3533-3536, 2001.

Hirata, K. and T. Baba, Transient thermal response in ocean bottom pressure measurement, Geophys. Res. Lett., 33, L10606, doi:10.1029/2006GL026084, 2006.

Hirata, K., M. Aoyagi, H. Mikada, K. Kawaguchi, Y. Kaiho, R. Iwase, S. Morita, I. Fujisawa, H. Sugioka, K. Mitsuzawa, K. Suehiro, H. Kinoshita, and N. Fujiwara, Real-time geophysical measurements on the deep seafloor using submarine cable in the southern Kurile subduction zone, IEEE J. Oceanic Eng., 27, 170-181, 2002.

Hirata, K., H. Takahashi, E. Geist, K. Satake, Y. Tanioka, H. Sugioka, and H. Mikada, Source depth dependence of micro-tsunamis recorded with ocean-bottom pressure gauges: The January 28, $2000 \mathrm{Mw} 6.8$ earthquake off Nemuro Peninsula, Japan, Earth Planet. Sci. Lett., 208, 305-318, 2003.

Hirata, K., H. Takayama, H. Tsushima, Y. Hayashi, R. Iwase, and T. Baba, Integration of seafloor geodetic observation and offshore tsunami observation - toward researches on tsunami forecast, Proc. 21 st Ocean Eng. Symp., OES21-181, 2009.

Houston, M. H. and J. M. Paros, High accuracy pressure instrumentation for underwater applications, Proc. 1998 Int. Symp. Underwater Technol., 307-311, 1998.

Irish, J. D. and F. E. Snodgrass, Quartz crystals as multipurpose oceanographic sensors-I. Pressure, Deep-Sea Res., 19, 165-169, 1972.

Ishiguro, M., T. Sato, Y. Tamura, and M. Ooe, Tidal data analysis-an introduction to BAYTAP, Proc. Inst. Stat. Math., 32, 71-85, 1984 (in Japanese with English abstract).

Isozaki, I., N. Den, T. Inuma, H. Matsumoto, M. Takahashi, and T. Tsukakoshi, Deep sea pressure observation and its application to pelagic tide analysis, Pap. Meteorol. Geophys., 31, 87-96, 1980.

Iwase, R., K. Asakawa, H. Mikada, T. Goto, K. Mitsuzawa, K. Kawaguchi, K. Hirata, and Y. Kaiho, Off Hatsushima Island observatory in Sagami Bay: Multidisciplinary long term observation at cold seepage site with underwater mateable connectors for future use, Proc. 3rd Int. Works. Sci. Use Submar. Cables Related Technol., 31-34, 2003.

Joseph, A., Tsunamis: Detection, Monitoring, and Early-Warning Technologies, 436 pp., Academic Press, Oxford, 2011.

Kanazawa, T. and A. Hasegawa, Ocean-bottom observatory for earthquakes and tsunami off Sanriku, north-east Japan using submarine cable, Proc. Int. Works. Sci. Use Submar. Cables, 208-209, 1997.

Kang, S. K., J.-Y. Chung, S.-R. Lee, and K.-D. Yum, Seasonal variability of the $\mathrm{M}_{2}$ tide in the seas adjacent to Korea, Cont. Shelf Res., 15, 10871113, 1995.

Kang, S. K., M. G. G. Foreman, H.-J. Lie, J.-H. Lee, J. Cherniawsky, and K.-D. Yum, Two-layer tidal modeling of the Yellow and East China Seas with application to seasonal variability of the $\mathrm{M}_{2}$ tide, J. Geophys. Res.-Oceans, 107, C33020, 10.1029/2001JC000838, 2002.

Karrer, H. E. and J. Leach, A quartz resonator pressure transducer, IEEE Trans. Ind. Electron. Control Instrum., 16, 44-50, 1969.

Leeuwenburgh, O., O. B. Andersen, and V. Huess, Seasonal tide variations from tide gauges and altimetry, Phys. Chem. Earth (A), 24, 403-406, 1999.

Matsumoto, H., T. Ohmachi, and K. Suyehiro, Micro-tsunami detected by cabled ocean-bottom tsunami meters off Sanriku, Proc. 3rd Int. Works. Sci. Use Submar. Cables Related Technol., 107-110, 2003.

Matsumoto, K., T. Takanezawa, and M. Ooe, Ocean tide models developed by assimilating TOPEX/POSEIDON altimeter data into hydrodynamical model: A global model and a regional model around Japan, $J$. Oceanogr., 56, 567-581, 2000. 
Matsumoto, K., T. Sato, H. Fujimoto, Y. Tamura, M. Nishino, R. Hino, T. Higashi, and T. Kanazawa, Ocean bottom pressure observation off Sanriku and comparison with ocean tide models, altimetry, and barotropic signals from ocean models, Geophys. Res. Lett., 33, L16602, doi:10.1029/2006GL026706, 2006.

Matsumoto, Y., T. Ishikawa, M. Fujita, M. Sato, H. Saito, M. Mochizuki, T. Yabuki, and A. Asada, Weak interplate coupling beneath the subduction zone off Fukushima, NE Japan, inferred from GPS/acoustic seafloor geodetic observation, Earth Planets Space, 60, e9-e12, 2008.

Mofjeld, H. O. and M. Wimbush, Bottom pressure observations in the Gulf of Mexico and Carribbean Sea, Deep-Sea Res., 24, 987-1004, 1977.

Momma, H., N. Fujisawa, K. Kawaguchi, R. Iwase, S. Suzuki, and H. Kinoshita, Monitoring system for submarine earthquakes and deep sea environment, Proc. Oceans 1997 Mar. Technol. Soc. IEEE Techno-Ocean 1997, 1453-1459, 1997.

Munk, W. H. and B. D. Zetler, Deep-sea tides: a problem, Science, 158, 884-886, 1967.

Munk, W. H., B. D. Zetler, and G. W. Groves, Tidal cusps, Geophys. J. Roy. Astron. Soc., 10, 211-219, 1965.

Nakamura, S., Digital Filtering for Beginners, 178 pp., Tokyo Denki University Press, Tokyo, 1989 (in Japanese).

Niiler, P. P., J. Filloux, W. T. Liu, R. M. Samelson, J. D. Paduan, and C. A. Paulson, Wind-forced variability of the deep eastern north Pacific: Observations of seafloor pressure and abyssal currents, J. Geophys. Res.-Oceans, 98, 22589-22602, 1993.

Nooner, S. L. and W. W. Chadwick Jr., Volcanic inflation measured in the caldera of Axial Seamount: Implications for magma supply and future eruptions, Geochem. Geophys. Geosyst., 10, Q02002, doi:10.1029/2008GC002315, 2009.

Osafune, S. and I. Yasuda, Bidecadal variability in the intermediate waters of the northwestern subarctic Pacific and the Okhotsk Sea in relation to 18.6-year period nodal tidal cycle, J. Geophys. Res.-Oceans, 111, C05007, doi:10.1029/2005JC003277, 2006

Park, J.-H. and D. R. Watts, Response of the southwestern Japan/East Sea to atmospheric pressure, Deep-Sea Res., 52, 1671-1683, 2005.

Park, J.-H., D. R. Watts, K. A. Donohue, and S. R. Jayne, A comparison of in situ bottom pressure array measurements with GRACE estimates in the Kuroshio Extension, Geophys. Res. Lett., 35, L17601, doi:10.1029/2008GL034778, 2008.

Polster, A., M. Fabian, and H. Villinger, Effective resolution and drift of Paroscientific pressure sensors derived from long-term seafloor measurements, Geochem. Geophys. Geosyst., 10, Q08008, doi:10.1029/2009GC002532, 2009

Pugh, D. T., Tides, Surges, and Mean Sea-Level: A Handbook for Engineers and Scientists, 472 pp., John Wiley, Chichester, 1987.

Ray, R. D., Secular changes of the $\mathrm{M}_{2}$ tide in the Gulf of Maine, Cont. Shelf Res., 26, 422-427, 2006.

Ray, R. D., Decadal climate variability: Is there a tidal connection?, $J$. Clim., 20, 3542-3560, 2007.

Saito, T., T. Matsuzawa, K. Obara, and T. Baba, Dispersive tsunami of the 2010 Chile earthquake recorded by the high-sampling-rate ocean-bottom pressure gauges, Geophys. Res. Lett., 37, L23303, doi:10.1029/2010GL045290, 2010.

Satake, K., T. Baba, K. Hirata, S. Iwasaki, T. Kato, S. Koshimura, J. Takenaka, and Y. Terada, Tsunami source of the 2004 off the Kii Peninsula earthquakes inferred from offshore tsunami and coastal tide gauges, Earth Planets Space, 57, 173-178, 2005.

Sato, M., H. Saito, T. Ishikawa, Y. Matsumoto, M. Fujita, M. Mochizuki, and A. Asada, Restoration of interplate locking after the
2005 Off-Miyagi Prefecture earthquake, detected by GPS/acoustic seafloor geodetic observation, Geophys. Res. Lett., 38, L01312, doi:10.1029/2010GL045689, 2011.

SCOR Working Group No. 27, An intercomparison of open sea tidal pressure sensors, UNESCO Tech. Pap. Mar. Sci. No. 21, 67 pp., 1975.

Spencer, R. and J. M. Vassie, The evolution of deep ocean pressure measurements in UK, Prog. Oceanogr., 40, 423-435, 1997.

Takahashi, M., Telemetry bottom pressure observation system at a depth of 2,200 meter, J. Phys. Earth, 29, 77-88, 1981a.

Takahashi, M., Real-time observation of precursory crustal level change by use of bottom pressure, J. Phys. Earth, 29, 421-433, 1981 b.

Tamura, Y., Some problems of coastal tides from a viewpoint of Earth tide researches, Bull. Coast. Oceanogr., 23, 49-59, 1985 (in Japanese).

Tamura, Y., A harmonic development of the tide-generating potential, Bull. Info. Mar. Terrest., 99, 6813-6855, 1987.

Tamura, Y., M. Ooe, and M. Takahashi, Spectra of ocean tides off Tokai region, central Japan, Mar. Sci. Mon., 18, 442-447, 1986 (in Japanese).

Tamura, Y., T. Sato, M. Ooe, and M. Ishiguro, A procedure for tida analysis with a Bayesian information criterion, Geophys. J. Int., 104, 507-516, 1991.

Tanioka, Y., Analysis of the far-field tsunamis generated by the 1998 Papua New Guinea Earthquake, Geophys. Res. Lett., 26, 3393-3396, 1999.

Tanioka, Y., K. Hirata, R. Hino, and T. Kanazawa, Slip distribution of the 2003 Tokachi-oki earthquake estimated from tsunami waveform inversion, Earth Planets Space, 56, 373-376, 2004.

Tsushima, H., R. Hino, H. Fujimoto, Y. Tanioka, and F. Imamura, Nearfield tsunami forecasting from cabled ocean bottom pressure data, $J$ Geophys. Res.-Solid Earth, 114, B06309, doi:10.1029/2008JB005988, 2009.

Uchida, H. and S. Imawaki, Estimation of the sea level trend south of Japan by combining satellite altimeter data with in situ hydrographic data, J. Geophys. Res.-Oceans, 113, C09035, doi:10.1029/2008JC004796, 2008.

Ward, S. N., Tsunamis, in Encyclopedia of Physical Science and Technology (Third Edition), edited by R. A. Meyers, 17, p. 175-191, Academic Press, San Diego, 2001.

Watanabe, T., K. Tadokoro, S. Sugimoto, T. Okuda, R. Ikuta, M. Ando, D. Muto, A. Kimoto, and M. Kuno, Estimation of interplate coupling in the Kumano Basin along the Nankai Trough based on observation of seafloor crustal deformation: The current status and foresight, J. Geodetic. Soc. Jpn., 55, 39-51, 2009 (in Japanese with English abstract).

Watts, D. R. and H. Kontoyiannis, Deep-ocean bottom pressure measurements: Drift removal and performance, J. Atmos. Oceanic Technol., 7, 296-306, 1990

Wearn Jr., R. B. and N. G. Larson, Measurements of sensitivities and drift of Digiquartz pressure sensors, Deep-Sea Res., 29, 111-134, 1982.

Wearn Jr., R. B. and J. M. Paros, Measurements of dead weight tester performance using high resolution quartz crystal pressure transducers, Proc. 34th Int. Instrum. Symp., 1-8, 1988.

Woodworth, P. L., A survey of recent changes in the main components of the ocean tide, Cont. Shelf Res., 30, 1680-1691, 2010.

Wunsch, C., P. Heimbach, R. M. Ponte, I. Fukumori, and the ECCOGODAE Consortium Members, The global general circulation of the ocean estimated by the ECCO-Consortium, Oceanography, 22, 88-103, 2009

D. Inazu (e-mail: inazud@aob.gp.tohoku.ac.jp) and R. Hino 